\title{
Study of the Thermal Decomposition of PFPEs Lubricants on a Thin DLC Film Using Finitely Extensible Nonlinear Elastic Potential Based Molecular Dynamics Simulation
}

\author{
S. K. Deb Nath ${ }^{1,2,3}$ and C. H. Wong ${ }^{2}$ \\ ${ }^{1}$ Division of Mechanical and Automotive Engineering, Kongju National University, Republic of Korea \\ ${ }^{2}$ School of Mechanical and Aerospace Engineering, Nanyang Technological University, Singapore 639798 \\ ${ }^{3}$ Department of Mechanical Science and Bioengineering, Graduate School of Engineering Science, \\ Osaka University, Toyonaka, Osaka 560-8531, Japan \\ Correspondence should be addressed to S. K. Deb Nath; sankar_20005@yahoo.com
}

Received 30 December 2013; Revised 20 April 2014; Accepted 14 May 2014; Published 6 July 2014

Academic Editor: S. N. Piramanayagam

Copyright (c) 2014 S. K. Deb Nath and C. H. Wong. This is an open access article distributed under the Creative Commons Attribution License, which permits unrestricted use, distribution, and reproduction in any medium, provided the original work is properly cited.

Perfluoropolyethers (PFPEs) are widely used as hard disk lubricants for protecting carbon overcoat reducing friction between the hard disk interface and the head during the movement of head during reading and writing data in the hard disk. Due to temperature rise of PFPE Zdol lubricant molecules on a DLC surface, how polar end groups are detached from lubricant molecules during coating is described considering the effect of temperatures on the bond/break density of PFPE Zdol using the coarse-grained bead spring model based on finitely extensible nonlinear elastic potential. As PFPE Z contains no polar end groups, effects of temperature on the bond/break density (number of broken bonds/total number of bonds) are not so significant like PFPE Zdol. Effects of temperature on the bond/break density of PFPE Z on DLC surface are also discussed with the help of graphical results. How bond/break phenomenonaffects the end bead density of PFPE Z and PFPE Zdol on DLC surface is discussed elaborately. How the overall bond length of PFPE Zdol increases with the increase of temperature which is responsible for its decomposition is discussed with the help of graphical results. At HAMR condition, as PFPE Z and PFPE Zdol are not suitable lubricant on a hard disk surface, it needs more investigations to obtain suitable lubricant. We study the effect of breaking of bonds of nonfunctional lubricant PFPE $Z$, functional lubricants such as PFPE Zdol and PFPE Ztetrao, and multidented functional lubricants such as ARJ-DS, ARJ-DD, and OHJ-DS on a DLC substrate with the increase of temperature when heating of all of the lubricants on a DLC substrate is carried out isothermally using the coarse-grained bead spring model by molecular dynamics simulations and suitable lubricant is selected which is suitable on a DLC substrate at high temperature.

\section{Introduction}

The very first hard disk drive (HDD) introduced in 1957 was called the random access method of accounting and control (RAMAC) or IBM model 350, which contained 50 disks with a diameter of 24 inches and provided a data capacity of 5 megabytes (MB) and a data rate of 12.5 kilobytes (KB)/s. The areal density was about $2 \mathrm{Kbit} /$ in [1, 2]. In 1973, IBM 3340 was the first HDD to use low-mass ferrite sliders and lubricate disks, which contained two (or four) disks with a diameter of 14 inches and provided a data capacity of 35 (or 70) MB, a data of $0.8 \mathrm{MB} / \mathrm{s}$, and an areal density of $1.68 \mathrm{Mbit} / \mathrm{in}$
$[2,3]$. The further introduction of giant magneto resistive (GMR) heads has boosted the compound annual growth rate from $60 \%$ in 1998 to $100 \%$ [4] with $80 \mathrm{Gbit} / \mathrm{in}^{2}$ drive in production. Seagate complemented the $100 \mathrm{Gbit} / \mathrm{in}^{2}$ goal of extremely high density recording (EHDR) project [5] for the information storage industry consortium (INSIC). Heatassisted magnetic recording (so-called "HAMR"), which is still under development, describes an idea to read/write data on a highly stable media using a laser thermal assistance to possibly achieve the areal density as high as $50 \mathrm{Tbit} / \mathrm{in}^{2}$ with patterned bits unless unforeseen conditions intervene; the expansion of HDD industry will continue at a high rate in 
the future, because of the increasing demand of computers, growth of storage-hungry graphics and multiple application, and conversion of information from paper to the more accessible computer media. As recording density increases, the role of the lubricant on the HDD systems becomes increasingly important to reliability due to the drastic decrease in spacing between the head and disk. For example, ultrathin PFPE lubricant films protect the head disk interface from mechani$\mathrm{cal}$ and thermal damage during intermittent contacts between the head and disk [6]. Ultrathin perfluoropolyether (PFPE) films lubricate head and disk interfaces, thus enhancing the reliability of hard disk drive systems [7-11]. Due to their high chemical and thermal stability, low surface tension, and low vapor pressure, perfluoropolyethers (PFPEs) are commonly used as disk lubricants. HDD product developments deal with problems of lubricant uniformity, roughness, durability, and stability. To strongly stick lubricant molecules onto the disk surface, PFPE with polar end groups has been used as the lubricant for HDI. Chen et al. [12] demonstrated that the catalytic degradation process of $\mathrm{Zdol}$ in the presence of Lewis acid occurs most readily at the acetal units $\left(\mathrm{O}-\mathrm{CF}_{2}-\mathrm{O}\right)$ within the internal backbones $\left(\mathrm{CF}_{2} \mathrm{O}\right.$ and $\left.\mathrm{CF}_{2} \mathrm{CF}_{2} \mathrm{O}\right)$ instead of the end group functionals. During the sliding at the carboncoated slider/Zdol lubricated $\mathrm{CH}_{x}$ disk interface, frictional heating is the primary decomposition mechanism of $\mathrm{Zdol}$ [13]. Wei et al. [14] studied the decomposition mechanisms of a PFPE Zdol at the head/disk interface under sliding conditions using an ultrahigh vacuum tribometer equipped with a mass spectrometer. Karis et al. [15] investigated the degradation of two types of PFPEs ( $\mathrm{Y}$ and $\mathrm{Z}$ ) in a media mill with $\mathrm{ZrO}_{2}$ particles and examined the scission products adsorbed on the $\mathrm{ZrO}_{2}$ particles by Novotny et al. [16] and the functional group at the scissioned ends from $-\mathrm{CO}_{2}$. The possibility of the catalytic effect of $\mathrm{ZrO}_{2}$ on the PFPEs is that the $\mathrm{ZrO}_{2}$ was found by Koka et al. $[17,18]$ to have significant catalytic degradation actions either in heating tests of mixtures containing $\mathrm{ZrO}_{2}$ powder and PFPEs or in friction tests with $\mathrm{ZrO}_{2}$ slider. Many experiments demonstrate that PFPEs, subjected to electron irradiation, are easily decomposed into smaller fragments [19]. Vureus et al. [20] used low energy electrons to bombard PFPEs and observed that the electron decomposition of PFPEs occurs at an energy below their ionization potential (about $14 \mathrm{eV}$ ). It is well known that, in the presence of metal and metal oxide, the rapid degradation of PFPEs takes place at temperatures below their decomposition temperatures [21, 22]. So, far, two different mechanisms have been reported: one is the decomposition caused by Lewis acid sites, $[23,24]$ the other is the decomposition caused by nonLewis acid sites [25, 26]. Suzuki and Kennedy [27] found that the flash temperature generated at the head/disk interface for an $\mathrm{Al}_{2} \mathrm{O}_{3}$-TiC slider on a rigid thin film magnetic disk is about $150^{\circ} \mathrm{C}$ under $1 \mathrm{~N}$ impact load. Storm [28] reported that the flash temperature does not exceed $100^{\circ} \mathrm{C}$ at a load $50 \mathrm{mN}$ and a speed of $0.1 \mathrm{~m} / \mathrm{s}$. Reactions of three types of perfluoroalkylpolyether (PFPE) liquids were studied during sliding contact with stainless steel $\left(440^{\circ} \mathrm{C}\right)$ specimen under ultrahigh vacuum conditions [29]. Wear and degradation mechanisms of perfluoropolyether lubricants are studied using mass spectrometry and friction measurements during sliding in a high vacuum environment [30]. Zhao et al. [31] observed that the PFPE lubricant film can be bonded to disk surface by illuminating the lubricant film with ultraviolet (UV) light. During the sliding process, the illumination with UV light accelerates the decomposition of the lubricant, reducing the head disk interface durability and causing more gaseous fragments because low-energy electrons created by the illumination interact with the lubricant molecules, activating and breaking up the molecules [31]. Liu et al. [32] studied the catalytic decomposition of Fomblin $\mathrm{Zdol}$ in the presence of the Lewis acid $\mathrm{Al}_{2} \mathrm{O}_{3}$ using thermogravimetric analysis (TGA). Lewis acid catalysis [33-35], triboelectrons [36], and tribomechanical shearing [37, 38] have all been demonstrated to decompose PFPEs. The environment has noticeable influence on performance and durability of the PFPE lubricant that can be weakened at high humidity [39]. The effects of thermal bonding, velocity, and environment have been studied on microscale using an AFM [40-43]. Degradation study of PFPE lubricants on magnetic media using a mass spectrometer by Zhao and Bhushan [44, 45] revealed that triboelectric decomposition and mechanical scission are dominant mechanisms for lubricant degradation during sliding.

Classical reactive molecular dynamics (RMD) simulation was used to model the thermal decomposition of perfluorodimethyl ether $\left(\mathrm{CF}_{3} \mathrm{OCF}_{3}\right)$ in the temperature range from $1000 \mathrm{~K}\left(727^{\circ} \mathrm{C}\right)$ to $5000 \mathrm{~K}\left(4727^{\circ} \mathrm{C}\right)$, which is relevant as a simple molecule containing the necessary architectural elements to study the chemical stability of perfluoropolyether lubricants [46]. With the increase of the temperature, the rate of thermal decomposition of perfluorodimethyl ether increases [46]. A modified coarse-grained, bead spring model was used to investigate the effect of lubricant fragments on lubricant transfer from a rotating disk to a slider [47]. The simulation results indicate that full lubricant molecules cannot transfer to the slider surface for large enough slider to disk spacing [47]. To investigate the failure of poly(dimethylsiloxane) polymer (PDMS) at high temperatures and pressures and in the presence of various additives, Chenoweth et al. [48] expanded the ReaxFF reactive force field to describe carbonsilicon systems. From molecular dynamics simulations using ReaxFF, they found initial thermal decomposition products of PDMS to be $\mathrm{CH}_{3}$ radical and the associated polymer radical, indicating that decomposition and subsequent crosslinking of the polymer are initiated by Si-C cleavage [48].

The above analyses of degradation of lubricant on the hard disk interface using experimental studies are either by friction or by catalytic ingredient $\mathrm{AL}_{2} \mathrm{O}_{3}$. Very few theoretical studies are carried out to study the decomposition of hard disk lubricants in the literature. Detailed theoretical and experimental studies are necessary to find out the real causes of the decomposition of hard disk lubricant. In the present study, we consider the hard disk surface as a thin DLC film. Coarse-grained bead spring model is used to simulate the lubricant using molecular dynamic simulation. How bond/breaking phenomenon enhances the evaporation rate of nonfunctional lubricant PFPE Z, functional lubricants such as PFPE Zdol and PFPE Ztetraol, and multidented functional lubricants such as ARJ-DS, ARJ-DD, and OHJ-DS on 


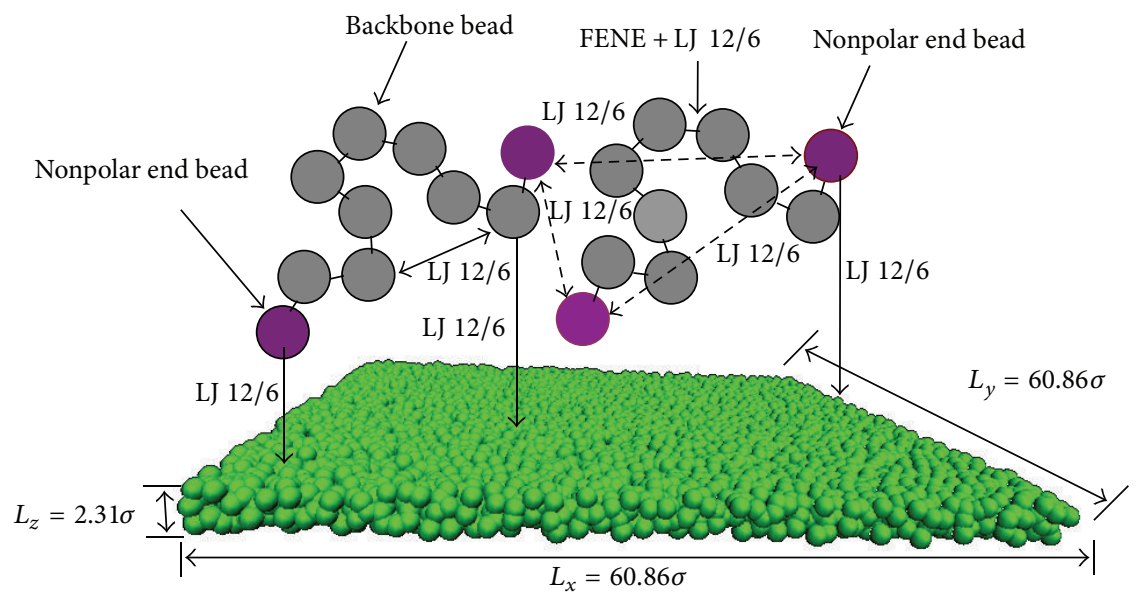

FIGURE 1: Coarse-grained bead spring model of nonfunctional lubricant PFPE Z on a DLC thin film [11].

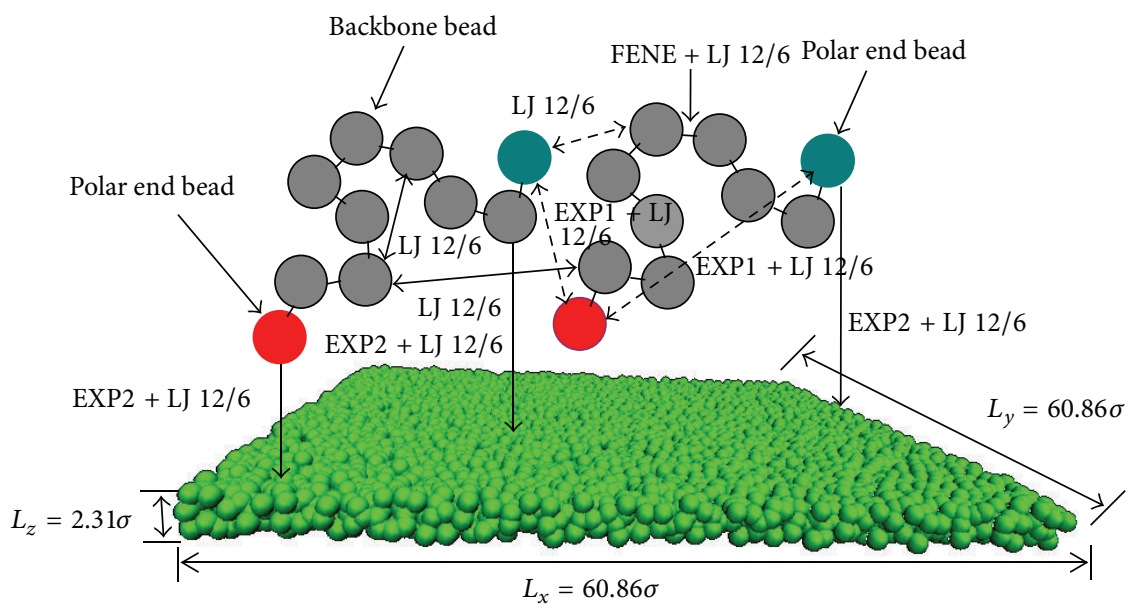

FIgURE 2: Coarse-grained bead spring model of functional lubricant PFPE Zdol on a DLC thin film [11].

a thin DLC film with temperature during coating is discussed in the present analysis. We also study the effects of temperature on the bond/breaking phenomenon of nonfunctional lubricant PFPE Z, functional lubricants such as PFPE Zdol and PFPE Ztetraol, and multidented functional lubricants such as ARJ-DS, ARJ-DD, and OHJ-DS as a function of temperature and we try to evaluate the mechanics of all of the lubricants mentioned here on a thin DLC substrate with the increase of temperature by the theoretical study. From the present study we select the appropriate lubricant from all of the lubricants mentioned here which is stable on a hard disk carbon overcoat at HAMR condition.

\section{Theoretical Formulation}

Hard disk lubricants such as PFPE Z, PFPE Zdol, PFPE Ztetraol, ARJ-DS, ARJ-DD, and OHJ-DS on the DLC film are simulated considering the coarse-grained bead spring model using finitely extensible nonlinear elastic potential (FENE) and the nonbonded potential LJ 12/6. As for example, Figure 1 shows the coarse-grained bead spring model of the nonfunctional lubricant PFPE $\mathrm{Z}$ on a thin DLC substrate, and Figure 2 shows the coarse-grained bead spring model of PFPE Zdol on a thin DLC film. $U_{\mathrm{bb}-\mathrm{bb}}$ is the interaction potential energy between two backbone beads of the same lubricant molecule or different lubricant molecules. $U_{\mathrm{fb}-\mathrm{fb}}$ is the interaction potential energy between two functional beads of the same lubricant molecule or different lubricant molecules; $U_{\mathrm{nfb}-\mathrm{nfb}}$ is the interaction potential energy between two nonfunctional beads of the same lubricant molecule or different lubricant molecules; $U_{\mathrm{bb}-\mathrm{dlc}}$ is the interaction potential energy between the backbone bead of a lubricant molecule and the DLC C atom; $U_{\text {nfb-dlc }}$ is the interaction potential energy between the nonfunctional beads of a lubricant molecule and the DLC film C atoms; $U_{\mathrm{fb}-\mathrm{dlc}}$ is the interaction potential energy between the functional beads of a lubricant molecule and the DLC film C atoms as shown in Figures 1 and 2 .

2.1. Theoretical Formulation of Nonfunctional Lubricant on the DLC Film. To simulate a nonfunctional lubricant molecule PFPE $Z$ on a DLC substrate, a coarse-grained bead spring model [11, 49-51] is used, which neglects the detailed atomistic information while keeping the essence of molecular 


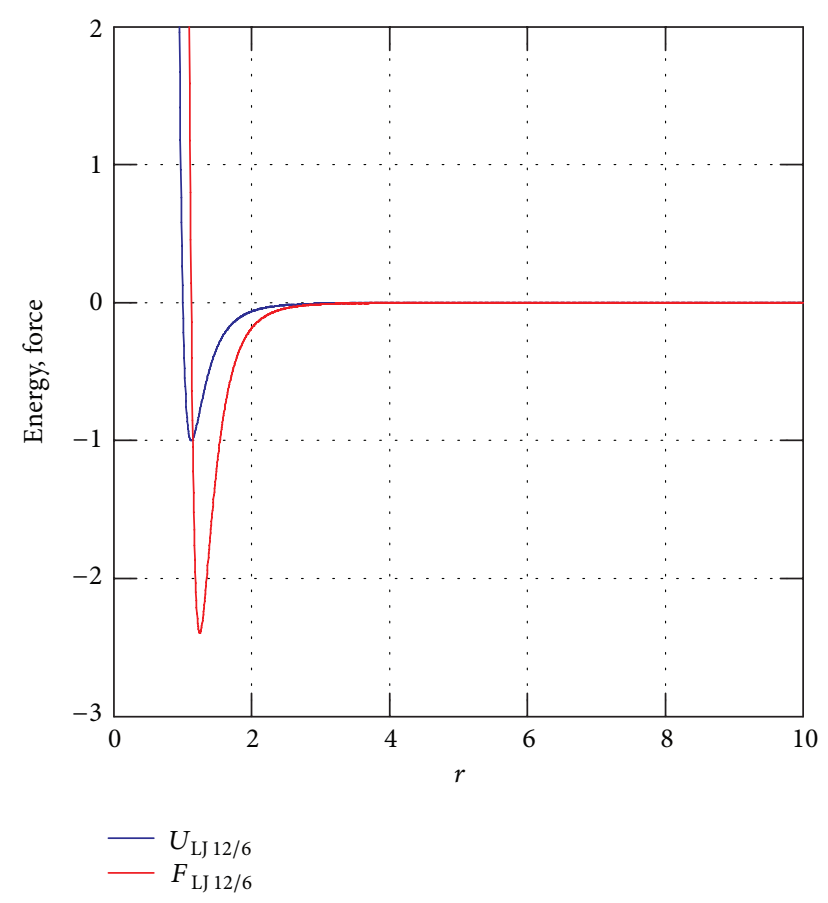

FIGURE 3: Energy, force relationship of nonfunctional bead to nonfunctional bead, nonfunctional bead to functional bead, and nonfunctional bead to DLC C atoms as a function of $r$.

structure based on finitely extensible nonlinear elastic potential and nonbonded Lennard-Jones (LJ) potential as shown in Figure 3. The expression of finitely extensible nonlinear elastic potential is

$$
U_{\mathrm{FENE}}=-\frac{1}{2} K R_{0}^{2} \ln \left[1-\left(\frac{r}{R_{0}}\right)^{2}\right] .
$$

It is used for calculating bonded energy between two adjacent beads of each lubricant molecule, where $K=40 \varepsilon / \sigma^{2}$ is the spring constant. $R_{0}$ is the maximum extended bond length and $r$ is the interbead distance (i.e., the bond length between adjacent beads). $R_{0}=1.5 \sigma, \sigma=1.0, \varepsilon=1.0$. The expression of nonbonded potential LJ 12/6 is

$$
U_{\mathrm{LJ} 12 / 6}=4 \varepsilon\left[\left(\frac{\sigma}{r}\right)^{12}-\left(\frac{\sigma}{r}\right)^{6}\right] .
$$

Here, $\sigma$ is the Lennard-Jones diameter of beads and $\varepsilon$ is the potential depth.

The expression given in (2) is used to calculate $U_{\mathrm{nfb}-\mathrm{nfb}}$, $U_{\mathrm{bb}-\mathrm{bb}}, U_{\mathrm{bb}-\mathrm{dlc}}$, and $U_{\text {nfb-dlc }}$ for nonfunctional lubricants, PFPE Z.

\subsection{Theoretical Formulation of Functional Lubricants on the} DLC Film. To simulate functional lubricant molecules such as PFPE Zdol, PFPE Ztetraol, ARJ-DS, ARJ-DD, and OHJDS, a coarse-grained bead spring model [11, 49-51] is used, which neglects the detailed atomistic information while keeping the essence of molecular structure based on the finitely extensible nonlinear elastic potential, nonbonded potential

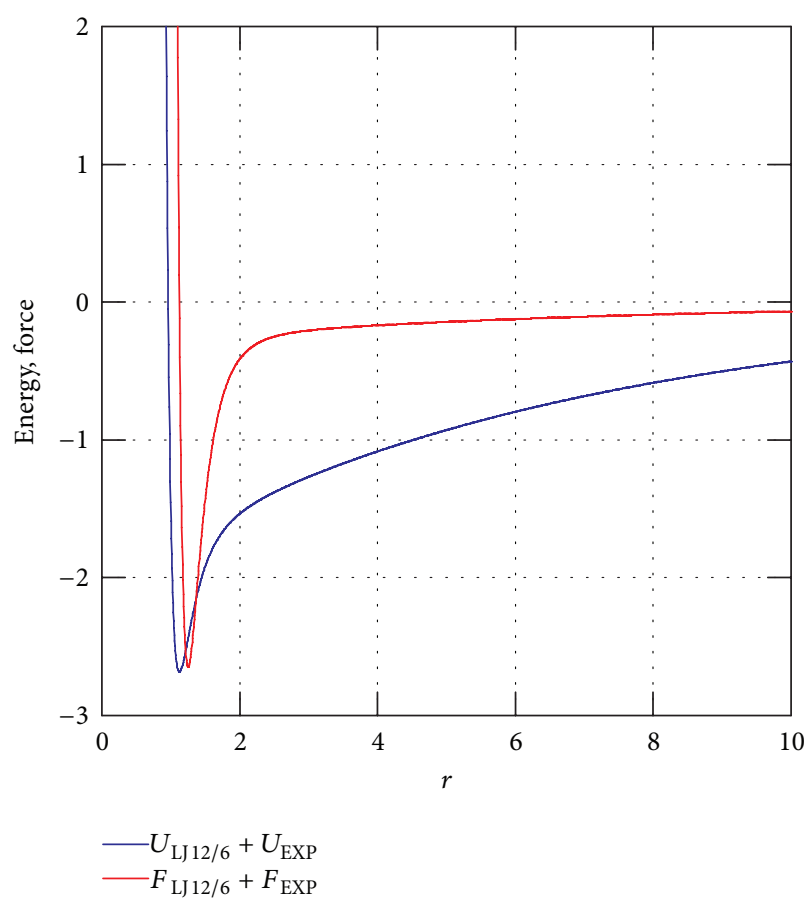

FIGURE 4: Energy, force relationship of functional bead to functional bead and functional bead to DLC C atoms as a function of $r$.

LJ 12/6, and the exponential potential as shown in Figure 4 $[11,52]$. The expression of an exponential potential for the interaction between two functional beads of functional lubricants is

$$
U_{\mathrm{EXP} 1}=-\varepsilon_{p}\left(-\frac{r}{d}\right) .
$$

The expression of an exponential potential for the interaction between the DLC $\mathrm{C}$ atom and the functional beads of functional lubricants is

$$
U_{\mathrm{EXP} 2}=-\varepsilon_{p}^{\mathrm{dlc}}\left(-\frac{r}{d}\right) .
$$

Kasai et al. [53] postulated that the bonding between PFPE Zdol and sputtered carbon occurs when a hydrogen atom is transferred from a hydroxyl end group of PFPE Zdol to a dangling bond site shielded inside the $S p^{3}$ type (diamondlike) granules of sputtered carbon. A recent reported result on vacuum deposition of PFPE Zdol clearly revealed the predicted spontaneous bonding and presently conducted analyses by TOF-SIMS of disks lubricated with PFPE Zdol revealed unambiguous evidence for the predicted decrease of the hydroxyl hydrogen and the emergence of the postulated alkoxyl units as the bonding of PFPE Zdol increases [54]. As some dangling bonds in the DLC surface exist, functional beads are attracted towards the DLC surface due to occupying the dangling bond with hydrogen from their $\mathrm{OH}$ group and forming an ionic bond with the DLC surface. And for this reason, an extra attractive potential is added with the Van der Waals interactions to satisfy the conditions [52]. 
The expression of combined nonbonded potential LJ 12/6 and exponential potential for the interaction between the functional beads of functional lubricants is

$$
\begin{aligned}
U_{\mathrm{fb}-\mathrm{fb}} & =U_{\mathrm{LJ} 12 / 6}+U_{\mathrm{EXP} 1} \\
& =4 \varepsilon\left[\left(\frac{\sigma}{r}\right)^{12}-\left(\frac{\sigma}{r}\right)^{6}\right]-\varepsilon_{p}\left(-\frac{r}{d}\right) .
\end{aligned}
$$

See [52]; $d$ is the correlation length and $\varepsilon_{p}$ is the potential depth between two functional beads. For our simulations, the polar potential depth is set to be $\varepsilon_{p}=2 \varepsilon$ between two functional beads and functional bead to DLC C atom interactions, where $\varepsilon$ is the potential depth parameter for the Lennard-Jones potential. When functional beads come towards DLC carbon atoms, it generates an extra attractive force, and to meet this requirement, an extra attractive potential is added with the Van der Waals interactions. The expression of combined nonbonded potential LJ 12/6 and exponential potential Chung et al. [52] for the interaction between the functional beads to DLC atoms is

$$
\begin{aligned}
U_{\mathrm{fb}-\mathrm{dlc}} & =U_{\mathrm{LJ} 12 / 6}+U_{\mathrm{EXP} 2} \\
& =4 \varepsilon\left[\left(\frac{\sigma}{r}\right)^{12}-\left(\frac{\sigma}{r}\right)^{6}\right]-\varepsilon_{p}^{\mathrm{dlc}}\left(-\frac{r}{d}\right) .
\end{aligned}
$$

See $[52] ; \varepsilon_{p}^{\mathrm{dlc}}=2 \varepsilon$ is the potential depth between the functional bead of a functional lubricant molecule and DLC $\mathrm{C}$ atom, where $\varepsilon$ is the potential depth parameter for the Lennard-Jones potential. To calculate $U_{\mathrm{bb}-\mathrm{bb}}, U_{\mathrm{bb}-\mathrm{dlc}}$ of functional lubricant, and PFPE Zdol, (2) is used.

2.3. Simulation Procedures. MD simulation results depend on the interaction potential and boundary conditions of the problems. If accurate interaction potential and boundary conditions are applied in the simulation, the results will be close to the exact results. We consider a coarse-grained bead spring model to simulate the hard disk lubricant. In the present head disk interface lubricant simulation, we first considered PPS boundary conditions $(P=$ periodic in $x$ direction, $P=$ periodic in $y$ direction, and $S=$ shrink wrapped in $z$ direction) considering the theoretical formulation for the nonfunctional and functional lubricant on a DLC thin film. The hard disk surface is considered as DLC (diamondlike carbon) which is obtained by heating and quenching the FCC or BCC diamond structures. Tersoff potential is used for the $\mathrm{C}-\mathrm{C}$ interaction of the DLC structure. To resist diffusion of nonfunctional lubricant PFPE $Z$, functional lubricants such as PFPE Zdol and PFPE Ztetraol, and multidented functional lubricants such as ARJ-DS, ARJDD, and OHJ-DS synthesized by Tani et al. [55] into DLC thin film during the simulation using coarse-grained bead spring model based on finitely extensible nonlinear elastic potential for lubricants, original DLC thin film is compressed into half of its original configuration in the $x, y$, and $z$ directions, respectively. To simulate nonfunctional and functional lubricant using the coarse-grained bead spring model based on finitely extensible nonlinear elastic potential and nonbonded potential LJ $12 / 6$, DLC thin film is compressed into half of its original configuration. The length, width, and thickness of the DLC film are $60.86 \sigma, 60.86 \sigma$, and $2.31 \sigma$. The used time step in the simulation is $0.005 \tau$ dimensionless, where $\tau\left(\varepsilon / m / \sigma^{2}\right)^{1 / 2}$; epsilon $=\varepsilon$, mass $=m$; sigma $=\sigma$. The number of $\mathrm{C}$ atoms in the film is 181004 . The total number of lubricant molecules used on the DLC film is 300 and each molecule contains 10 beads. Original chain length of each molecule is $9 \sigma$. The molecular weight of PFPE Z, PFPE Zdol, PFPE Ztetraol, ARJ-DS, ARJ-DD, and OHJ-DS are 3609.96 and $4533 \mathrm{gm} / \mathrm{mole}, 3216 \mathrm{gm} / \mathrm{mole}, 3599.88 \mathrm{gm} / \mathrm{mol}$, $2699.8752 \mathrm{gm} / \mathrm{mol}$, and $3700.272 \mathrm{gm} / \mathrm{mol}$, respectively. Mass of the beads of nonfunctional and functional lubricant molecules and DLC carbon atoms is considered as the ratio of original mass as we simulate the whole system in a nondimensional way. The results obtained from the simulation are dimensionless. Nonfunctional lubricant named as PFPE Z, functional lubricants such as PFPE Zdol and PFPE Ztetraol, and different types of multidented functional lubricants such as ARJ-DS, ARJ-DD, and OHJ-DS are heated on a DLC substrate from nondimensional temperature $T^{*}=1$ to $T^{*}=10$ isothermally. This nondimensional temperature can be converted using the parameters obtained by Li et al. [56] to obtain dimensional temperatures. According to the parameters obtained by Li et al. [56], $T^{*}=1=167 \mathrm{~K}=$ $-106^{\circ} \mathrm{C} ; T^{*}=2=334 \mathrm{~K}=61^{\circ} \mathrm{C} ; T^{*}=3=501 \mathrm{~K}=228^{\circ} \mathrm{C}$; $T^{*}=4=668 \mathrm{~K}=395^{\circ} \mathrm{C} ; T^{*}=5=835 \mathrm{~K}=562^{\circ} \mathrm{C}$; $T^{*}=6=1002 \mathrm{~K}=729^{\circ} \mathrm{C} ; T^{*}=7=1169 \mathrm{~K}=896^{\circ} \mathrm{C}$; $T^{*}=8=1336 \mathrm{~K}=1063^{\circ} \mathrm{C} ; T^{*}=9=1503 \mathrm{~K}=1230^{\circ} \mathrm{C}$; $T^{*}=10=1670 \mathrm{~K}=1397^{\circ} \mathrm{C}$.

\section{Results and Discussions}

Before coating PFPE Z, PFPE Zdol, PFPE Ztetraol, ARJDS, ARJ-DD, and OHJ-DS lubricant molecules on the hard disk surface, they experience only intermolecular interactions among them. Static and dynamic configurations of nonfunctional lubricant PFPE $\mathrm{Z}$ before coating on the hard disk surface should have some differences from functional lubricants such as PFPE Zdol, PFPE Ztetraol, ARJ-DS, ARJ$\mathrm{DD}$, and OHJ-DS because these functional lubricants have functional end groups; on the other hand PFPE $\mathrm{Z}$ has nonfunctional end groups. Not only the attraction force between functional beads is more than that between nonfunctional beads, but also this attraction force acts at a long distance for functional beads of functional lubricant like PFPE Zdol, PFPE Ztetraol, ARJ-DS, ARJ-DD, and OHJ-DS. During coating, nonfunctional lubricant PFPE $Z$ and functional lubricants such as PFPE Zdol, PFPE Ztetraol, ARJ-DS, ARJ$\mathrm{DD}$, and $\mathrm{OHJ}-\mathrm{DS}$ suddenly experience an extra interaction with the carbon atoms of coated DLC film on magnetic layer of the hard disk. As overcoat of the hard disk surface contains dangling bond, when functional beads come closer to the DLC surface, the functional beads experience higher attraction force compared to the other nonfunctional beads of the same lubricant molecule. Maximum extension of the bond of PFPE $\mathrm{Z}$ and PFPE $\mathrm{Zdol}$ is considered $1.5 \sigma(1.05 \mathrm{~nm})$ and if the bond exceeds this limit the bond will break (see Figures 5 and 6). As a result the bond attaching the beads extends more than that of the other bonds of the molecule. 


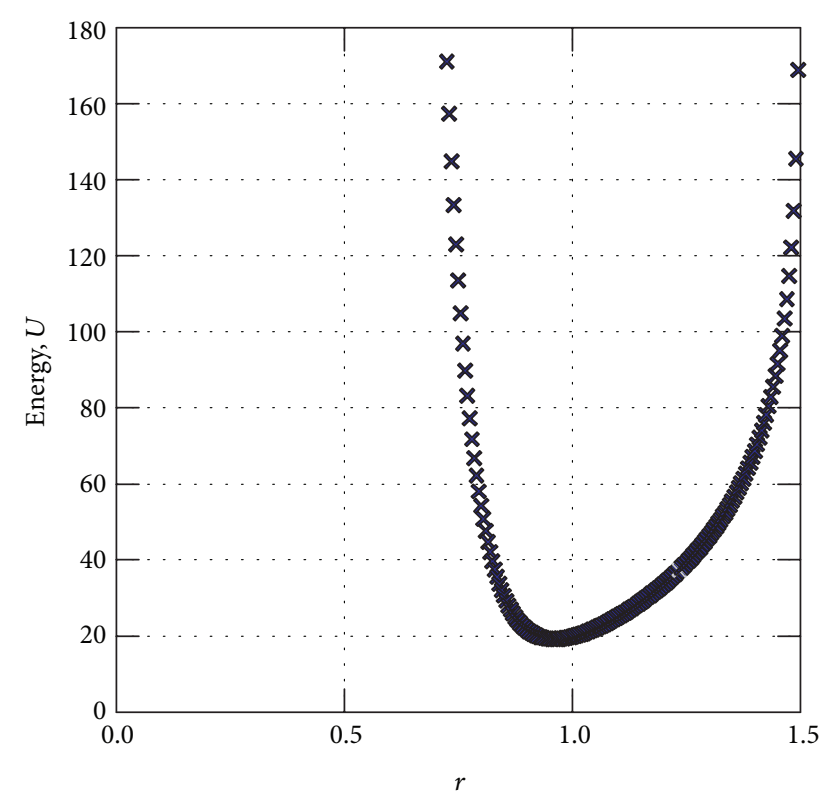

FIGURE 5: Total potential energy between two beads.

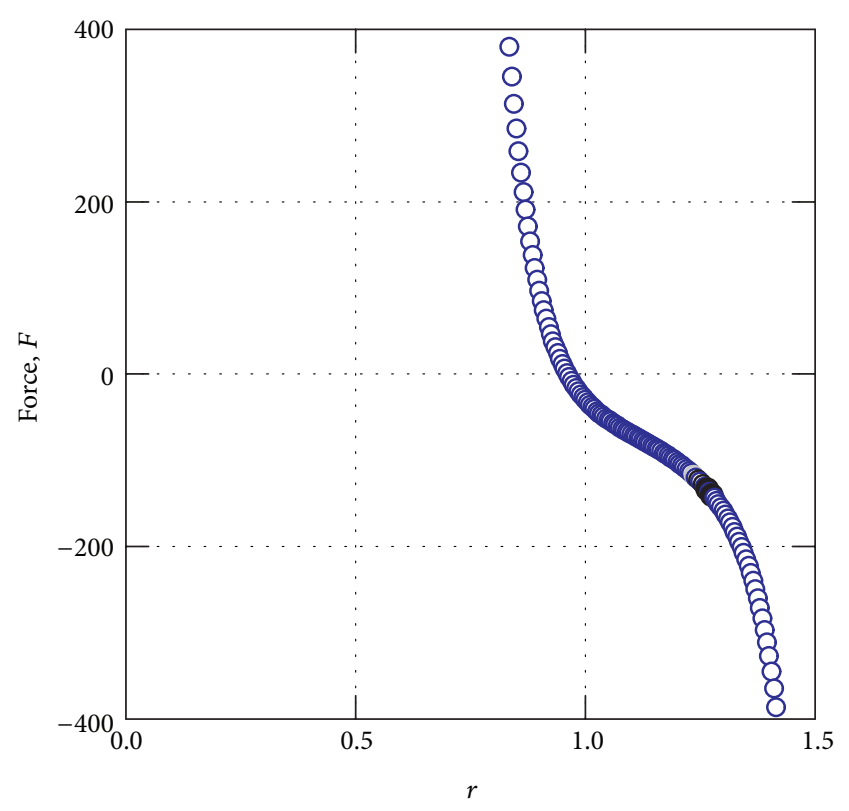

FIgURE 6: Total forces between two beads.

If the extension of the bond crosses a certain limit, it breaks. As a result, there is possibility to detach functional beads of PFPE Zdol from the molecular chain if there is an extreme environment that dominates during coating. But for nonfunctional lubricants, such type of bond/break phenomenon happens rarely. But the main drawback of nonfunctional lubricant is that nonfunctional lubricant PFPE $\mathrm{Z}$ on the hard disk carbon overcoat is very unstable because they are unable to form bond with the hard disk carbon overcoat due to nonfunctional beads. In the present analysis, we consider the thin DLC film having thickness $2 \sigma \quad(1.4 \mathrm{~nm}=14 \AA)$, film length $=60 \sigma(42 \mathrm{~nm})$, and film width $=60 \sigma(42 \mathrm{~nm})$.
The above nondimensional parameters are converted into dimensional parameter considering value of $\sigma=0.7 \mathrm{~nm}$ which is mentioned in the reference [57]. Effect of temperatures on the bond/break density of PFPE $Z$ and PFPE Zdol is discussed with the graphical results. With the increase of temperature, how the overall bond length increases is also discussed. Effects of bond/break on the end bead density of PFPE Zdol on the DLC substrate considering two cases such as bond/break and without bond/break are also studied. The number of beads of a lubricant chain for PFPE Z, PFPE Zdol, and PFPE Ztetraol is 10 and length of the lubricant molecule is $9 \sigma(6.3 \mathrm{~nm}=63 \AA)$. The functional beads of PFPE $\mathrm{Zdol}$ and PFPE Ztetraol are 2 and 4, respectively. The number of beads in each chain of ARJ-DS is 15; among these beads functional beads are 3 and total length of the chain is $14 \sigma$ $(8.9 \mathrm{~nm})$. The number of beads in each chain of ARJ-DD is 15 ; among these functional beads are 5 and total length of the chain is $14 \sigma(8.9 \mathrm{~nm})$. The number of beads in each chain of $\mathrm{OHJ}-\mathrm{DS}$ is 15 ; among these functional beads are 3 , and total length of the chain is $14 \sigma(8.9 \mathrm{~nm})$. From experimental result of different types of conventional hard disk lubricant on the hard disk surface at HAMR condition in DSI in Singapore, it is observed that lubricant films deteriorate very quickly. The main reason of loss of the lubricant on the hard disk surface is thermal decomposition or bond/break due to continuous heating of the hard disk lubricant as a result of HAMR condition. In the present analysis, bond/breaking phenomenon of nonfunctional lubricant PFPE Z, functional lubricants such as PFPE Zdol and PFPE Ztetraol, and multidented functional lubricants such as ARJ-DS, ARJ-DD, and OHJ-DD on a thin DLC film is studied.

Figures 7(a) and 7(b) illustrate the physical configuration of PFPE Z on a thin DLC film at temperature $T^{*}=7(1169 \mathrm{~K}$ $=896^{\circ} \mathrm{C}$ ) at steps 0 and 300,000 , respectively. Figures $7(\mathrm{c})$ and 7(d) illustrate the physical configuration of PFPE Zdol on a thin DLC film at temperature $T^{*}=7\left(1169 \mathrm{~K}=896^{\circ} \mathrm{C}\right)$ at steps 0 and 300,000, respectively. At temperature $T^{*}=$ $7\left(1169 \mathrm{~K}=896^{\circ} \mathrm{C}\right)$, most PFPE Z molecules fly away from the DLC substrate and some PFPE Zdol molecules fly away due to detaching of functional end groups from the lubricant molecules for the case of bond breaking. Figures 8(a) and 8(b) illustrate the overall extended bond length of PFPE Zdol on a thin DLC film beyond its allowable maximum bond length (see Figures 5 and 6) at temperatures $T^{*}=4$ $\left(668 \mathrm{~K}=395^{\circ} \mathrm{C}\right)$ and $T^{*}=7\left(1169 \mathrm{~K}=896^{\circ} \mathrm{C}\right)$, respectively. At the very beginning of the simulation (nearly 200 steps) the overall extended bond length is the highest and at this time, there is high possibility to break the bond, split the lubricant molecules, and convert them into shorts chains which are very unstable in high temperature like PFPE $\mathrm{Z}$. With the increasing steps, the overall extended bond length gradually decreases and the trend of this result shows that with time the bond breaking phenomenon of PFPE Zdol on the thin DLC film decreases. As the kinetic energy of beads of the lubricant molecules will increase with the increase of temperature, the overall extended bond length should increase with temperature and this phenomenon is observed as shown in Figure 8. Figure 9 illustrates the effects of bond/break on the functional end bead density of PFPE Zdol 


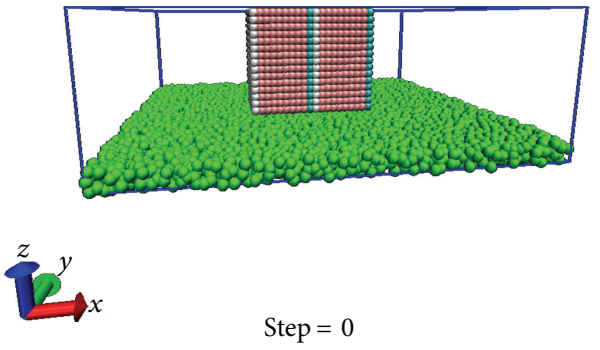

(a)

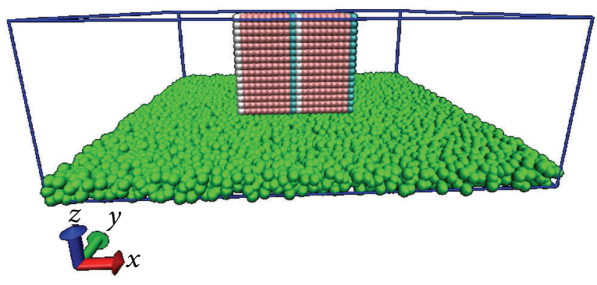

Step $=0$

(c)
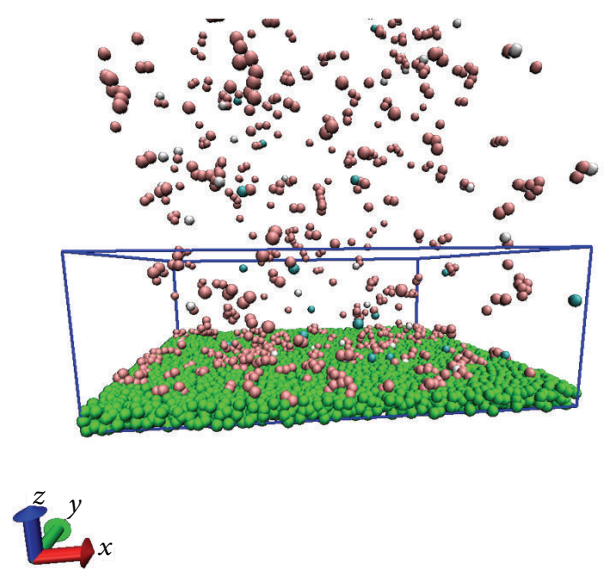

Step $=300,000$

(b)
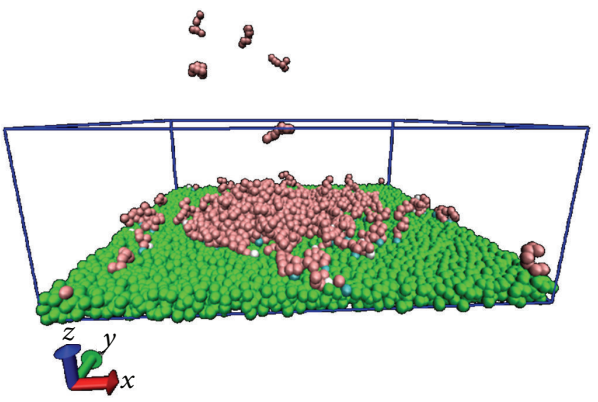

Step $=300,000$

(d)

Figure 7: (a) Snapshots of PFPE Z at step 0; (b) snapshots of PFPE Z at step 300,000; (b) snapshots of PFPE Zdol at step 0; (d) snapshots of PFPE Zdol on a DLC substrate at step 300,000 when the DLC film is compressed into half of its original configuration at temperature $T^{*}=7$ $\left(896 \mathrm{~K}=623^{\circ} \mathrm{C}\right)$ with bond/break.

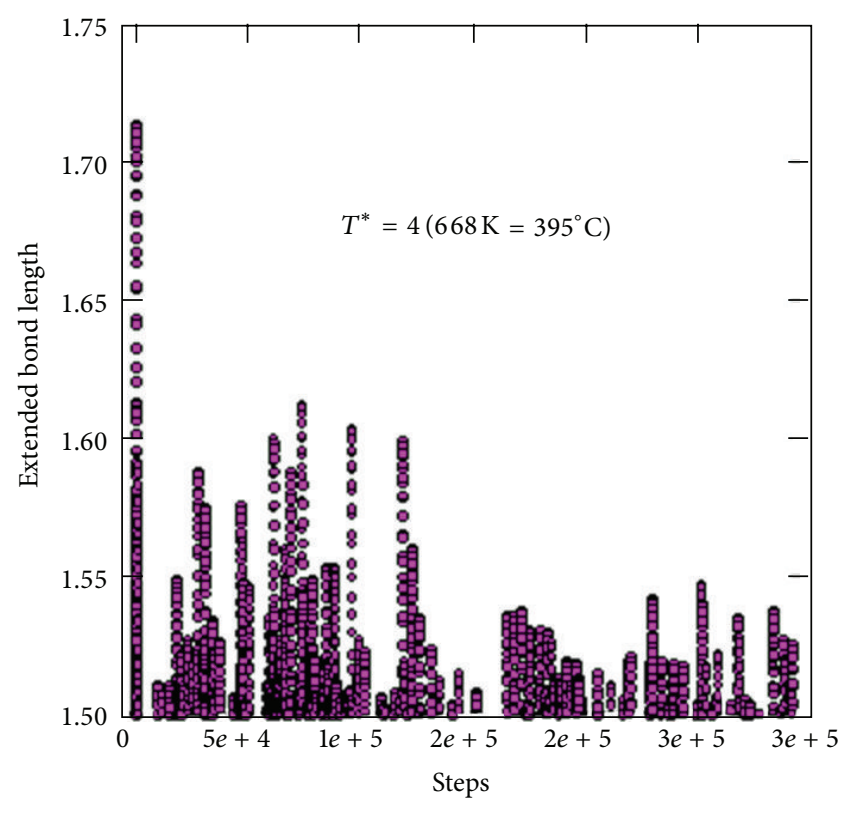

- $T^{*}=4$

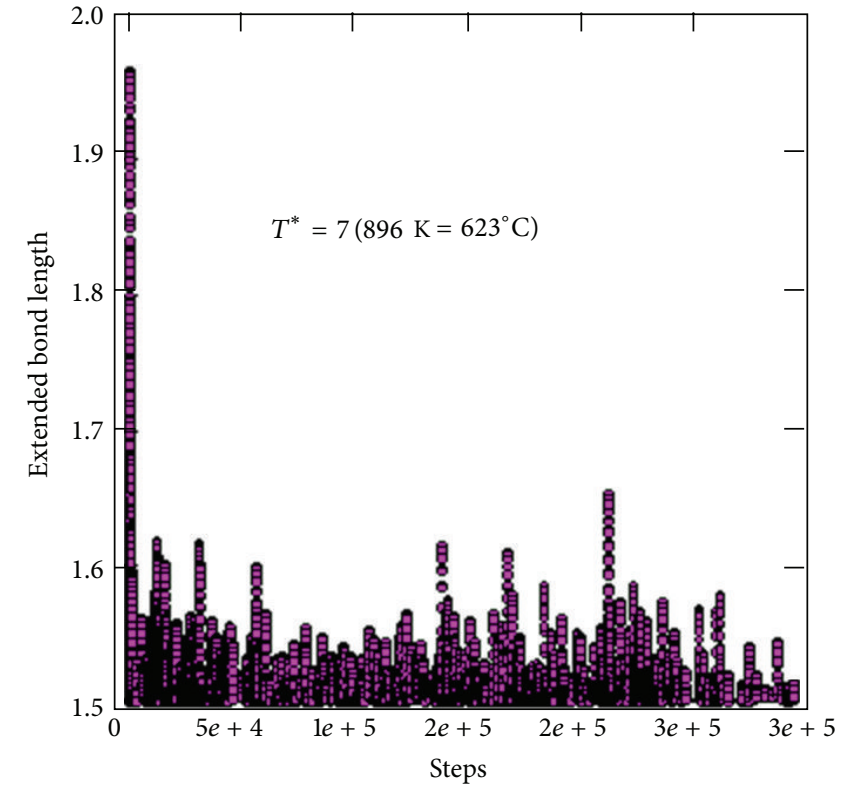

- $T^{*}=7$

(a)

(b)

FIGURE 8: Extended bond length of PFPE Zdol at different temperatures: (a) $T^{*}=4\left(668 \mathrm{~K}=395^{\circ} \mathrm{C}\right)$ and $(\mathrm{b}) T^{*}=7\left(896 \mathrm{~K}=623^{\circ} \mathrm{C}\right)$. 


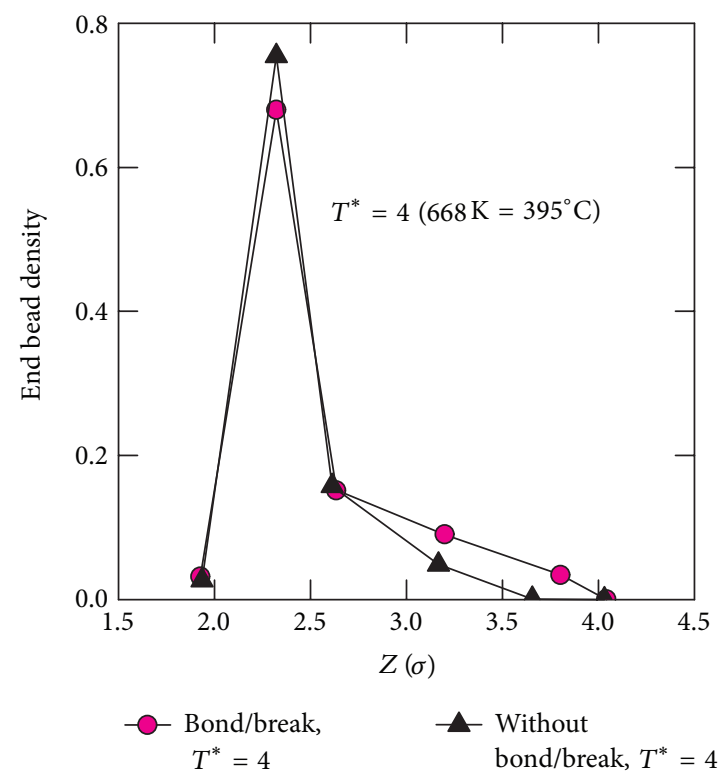

FIGURE 9: Effects of temperature on end bead density of PFPE Zdol lubricant molecules on a DLC substrate for the case of bond/break and without bond/break at temperature $T^{*}=4\left(668 \mathrm{~K}=395^{\circ} \mathrm{C}\right)$.

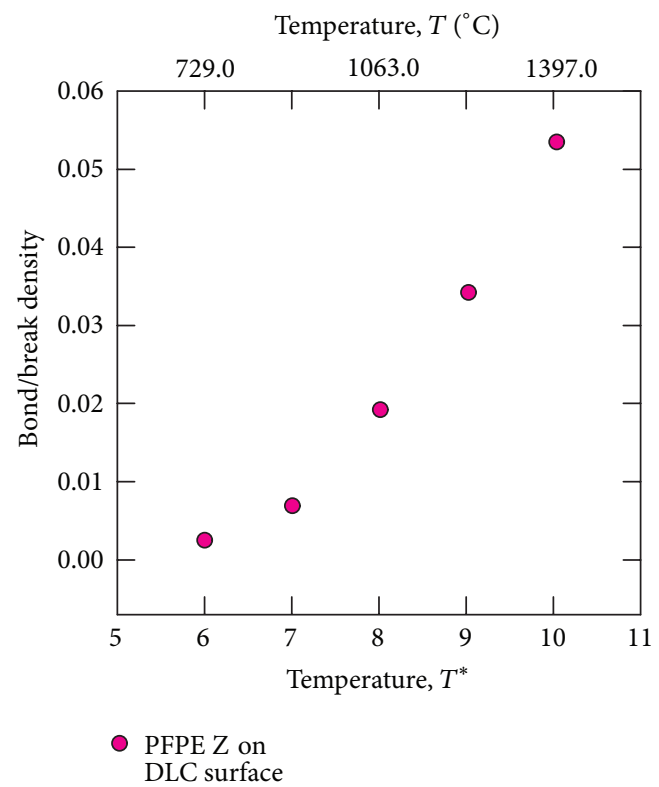

(a)

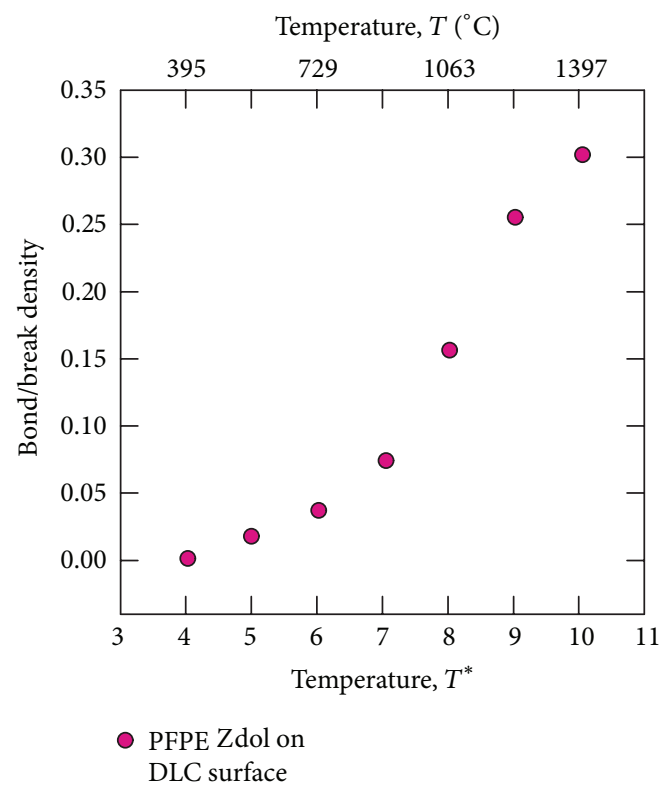

(b)

FIGURE 10: Effects of temperature on the bond/break density: (a) of PFPE Z; (b) of PFPE Zdol on a DLC substrate when the DLC film is compressed into half of its original size.

on the DLC substrate. Due to breaking of bonds of PFPE Zdol on a DLC substrate, the end bead density of the first layer of PFPE Zdol on a DLC substrate considering bond/break is lower than the end bead density of PFPE $\mathrm{Zdol}$ on a DLC substrate considering without the breaking of bonds of PFPE Zdol. Figures 10(a) and 10(b) show the effects of temperature on the bond/break density of PFPE $\mathrm{Z}$ and PFPE Zdol on the DLC film. With the increase of temperature the bond/break density of PFPE $\mathrm{Z}$ and PFPE Zdol increases but the bond/breaking density of PFPE Zdol is many times higher than that of PFPE $Z$ on the DLC film because there is less attraction force of end groups of PFPE Z on DLC surface than those of PFPE Zdol on the DLC film due to having nonfunctional end groups of PFPE $Z$.

To understand the behavior of thermal decomposition of PFPE Ztetraol on a DLC substrate, PFPE Ztetraol is heated on a DLC substrate isothermally at different temperatures considering bond/break phenomenon. As for example the snapshots of isothermally heated PFPE Ztetraol on a DLC substrate at a temperature $T^{*}=4\left(668 \mathrm{~K}=395^{\circ} \mathrm{C}\right)$ at different 

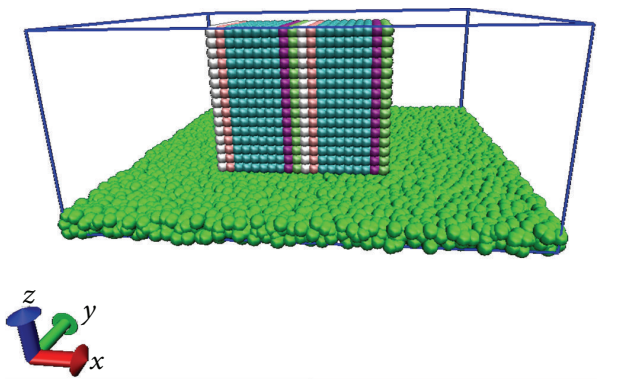

Step $=0$

(a)
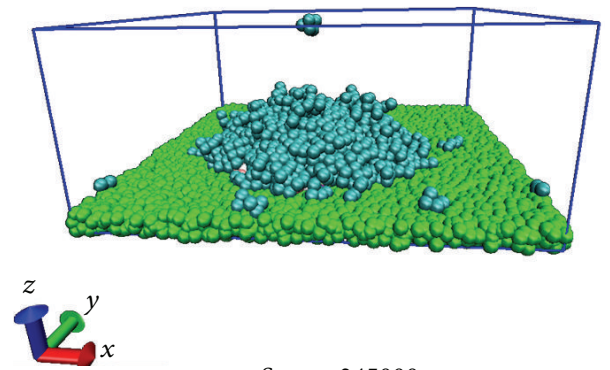
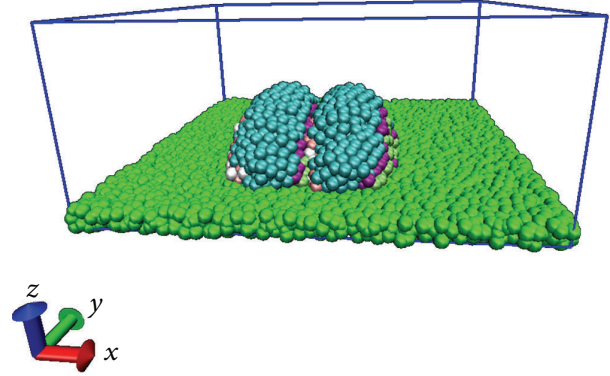

Step $=3000$

(b)
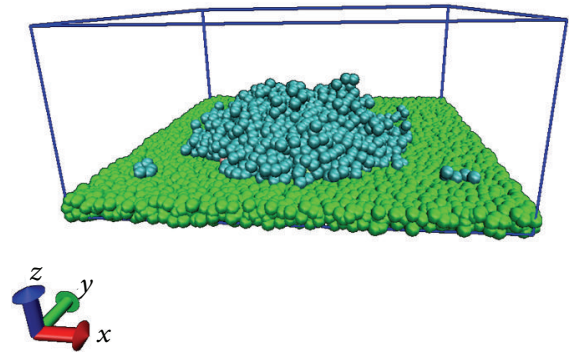

Step $=300,000$

(d)

FIGURE 11: Snapshots of PFPE Ztetraol on a DLC substrate at different time steps: (a) at step = 0; (b) at step = 3000; (c) at step = 245000; (d) at step $=300,000$ at temperature $T^{*}=3\left(501 \mathrm{~K}=228^{\circ} \mathrm{C}\right)$ with bond/break.

steps show how thermal desorption happens due to shortening of its chain length on account of bond/break as shown in Figure 11. Figure 12 illustrates the bond/break density of PFPE Ztetraol on a DLC substrate with the increase of temperature. From Figure 12(b), it is observed that with the increase of temperature the density of the breaking bonds of PFPE Ztetraol increases. From the temperature $T^{*}=1(167 \mathrm{~K}$ $\left.=-106^{\circ} \mathrm{C}\right)$ to $10\left(1670 \mathrm{~K}=1397^{\circ} \mathrm{C}\right)$, the rate of increasing of the density of breaking bonds of PFPE Ztetraol on a DLC substrate occurs at two different rates. The increasing rate of the density of breaking bonds of PFPE Ztetraol within the range $T^{*}=6\left(1002 \mathrm{~K}=729^{\circ} \mathrm{C}\right)$ to $10\left(1670 \mathrm{~K}=1397^{\circ} \mathrm{C}\right)$ is higher than that of the increasing rate of breaking bonds of PFPE Ztetraol within the range of temperature $T^{*}=1$ $\left(167 \mathrm{~K}=-106^{\circ} \mathrm{C}\right)$ to $6\left(1002 \mathrm{~K}=729^{\circ} \mathrm{C}\right)$. Temperature $T^{*}$ $=6\left(1002 \mathrm{~K}=729^{\circ} \mathrm{C}\right)$ is defined as the critical temperature for the thermal decomposition of PFPE Ztetraol because after this temperature, the rate of increasing of breaking bonds of PFPE Ztetraol suddenly increases. To understand the small variation of temperature on the breaking bonds of PFPE Ztetraol on a DLC substrate, the increasing rate of the breaking bonds of PFPE Ztetraol on a DLC substrate is investigated within the range of temperature $T^{*}=2.1(350.7 \mathrm{~K}$ $\left.=77.7^{\circ} \mathrm{C}\right)$ to $2.9\left(484.3 \mathrm{~K}=211.3^{\circ} \mathrm{C}\right)$ rising temperature $T^{*}=$ $0.1\left(16.7 \mathrm{~K}=-256.3^{\circ} \mathrm{C}\right)$ at per step shown in Figure 12(a). A fluctuation on the density of breaking bonds of PFPE Ztetraol molecules on a DLC substrate is observed when their density of breaking of bonds on a DLC substrate is studied at a very small range considering many steps as shown in Figure 12(a).

Now we study the thermal decomposition of different lubricants such as ARJ-DS, ARJ-DD, and OHJ-DS on a DLC substrate to select suitable multidented functional lubricants which is suitable to lubricate hard disk carbon overcoat at a very large temperature. Figure 13 shows the snapshots of ARJ-DS on a DLC substrate which is heated at temperature $T^{*}=4\left(668 \mathrm{~K}=395^{\circ} \mathrm{C}\right)$ at different steps. At 300,000 step no ARJ-DS lubricant molecules fly away from the DLC substrate due to breaking of bonds on account of their thermal decomposition. In ARJ-DS lubricant molecules, there exists one functional bead in the middle portion of each chain and at its two ends there exist two functional beads. Figure 14 illustrates the density of breaking bonds of ARJ-DS on a DLC substrate at different temperatures. Up to temperature $T^{*}=$ $4\left(668 \mathrm{~K}=395^{\circ} \mathrm{C}\right)$, the density of breaking bonds of ARJ-DS is nearly equal to zero which means up to temperature rise $T^{*}=4\left(668 \mathrm{~K}=395^{\circ} \mathrm{C}\right)$; no breaking of bonds of ARJ-DS lubricant molecules on a DLC substrate increases with the rise of temperature. ARJ-DS shows that the effect of temperature on the breaking of bonds is the lowest among all of the functional lubricant molecules on a DLC substrate.

ARJ-DD multidented functional lubricant molecules are heated on a DLC substrate isothermally at different 


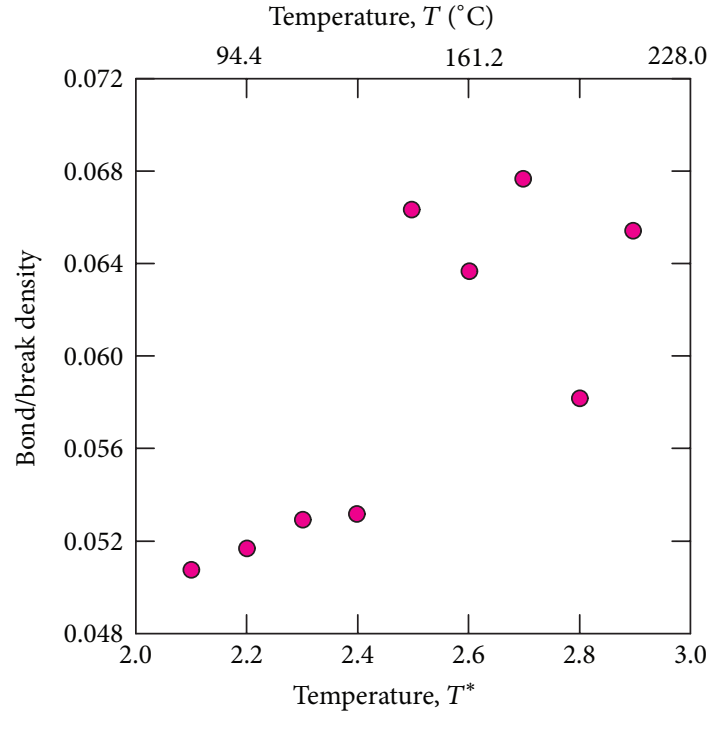

- Ztetrao

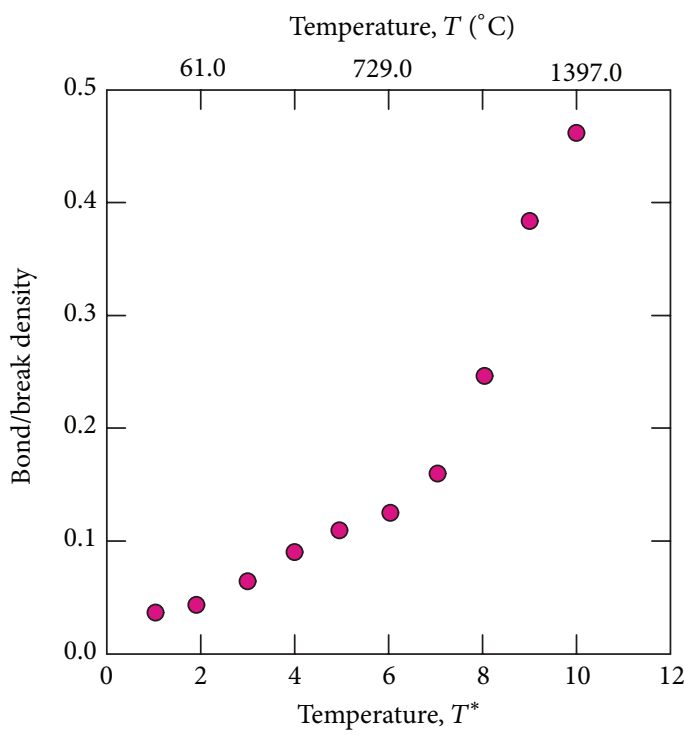

- Ztetrao

(a)

(b)

FIGURE 12: Effects of temperature on the bond/break density of PFPE Ztetraol on a DLC substrate: (a) at a short temperature range; (b) at a long temperature range.

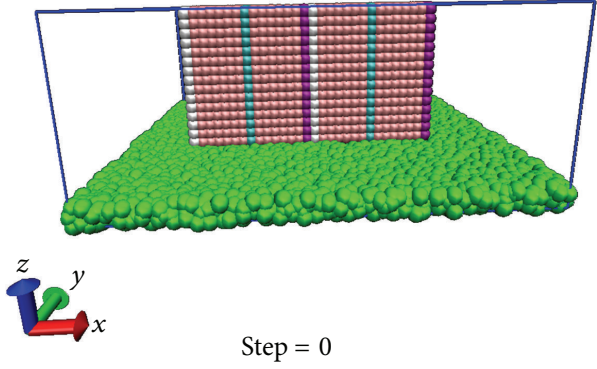

(a)
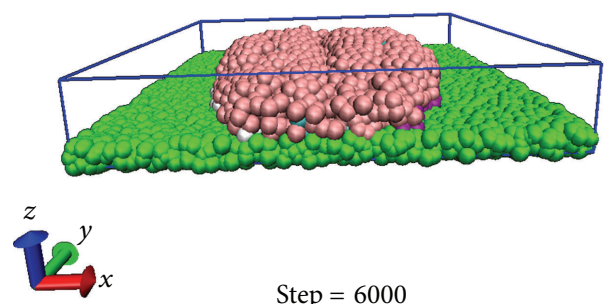

Step $=6000$

(b)
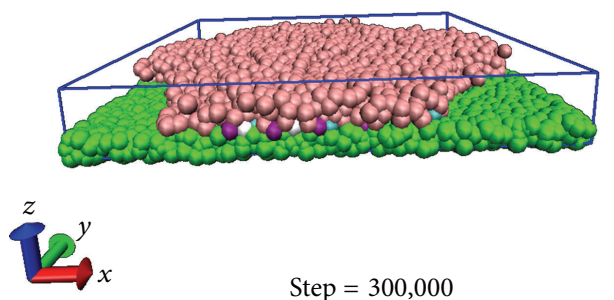

Step $=300,000$

(c)

FIGURE 13: Snapshots of ARJ-DS on a DLC substrate at different time steps: (a) step =0; (b) step =6000; (c) step = 300,000 at temperature $T^{*}$ $=4\left(668 \mathrm{~K}=395^{\circ} \mathrm{C}\right)$ with bond $/$ break.

temperatures and the effects of temperature on the density of their breaking of bonds are studied to understand their thermal decomposition on a DLC substrate. In ARJ-DD lubricant molecules, there are two functional beads in each end and two functional beads are remained at middle portion of the chain which connect to nonfunctional beads. Figure 15 illustrates the snapshots of ARJ-DD lubricant molecules on a DLC substrate when ARJ-DD lubricant molecules are heated on a DLC substrate isothermally at $T^{*}=4\left(\left(668 \mathrm{~K}=395^{\circ} \mathrm{C}\right)\right)$ considering bond/break. At 300,000 step, some lubricant molecules fly away due to shortening of chain length on account of breaking bonds. Figure 16 shows the density of breaking bonds of ARJ-DD lubricant molecules on a DLC substrate with temperature. With the increase of temperature, the density of breaking bonds of ARJ-DD lubricant molecules on a DLC substrate increases with temperature. Figure 17 shows the snapshots of OHJ-DS on a DLC substrate at a temperature $T^{*}=4\left(668 \mathrm{~K}=395^{\circ} \mathrm{C}\right)$ when it is heated 


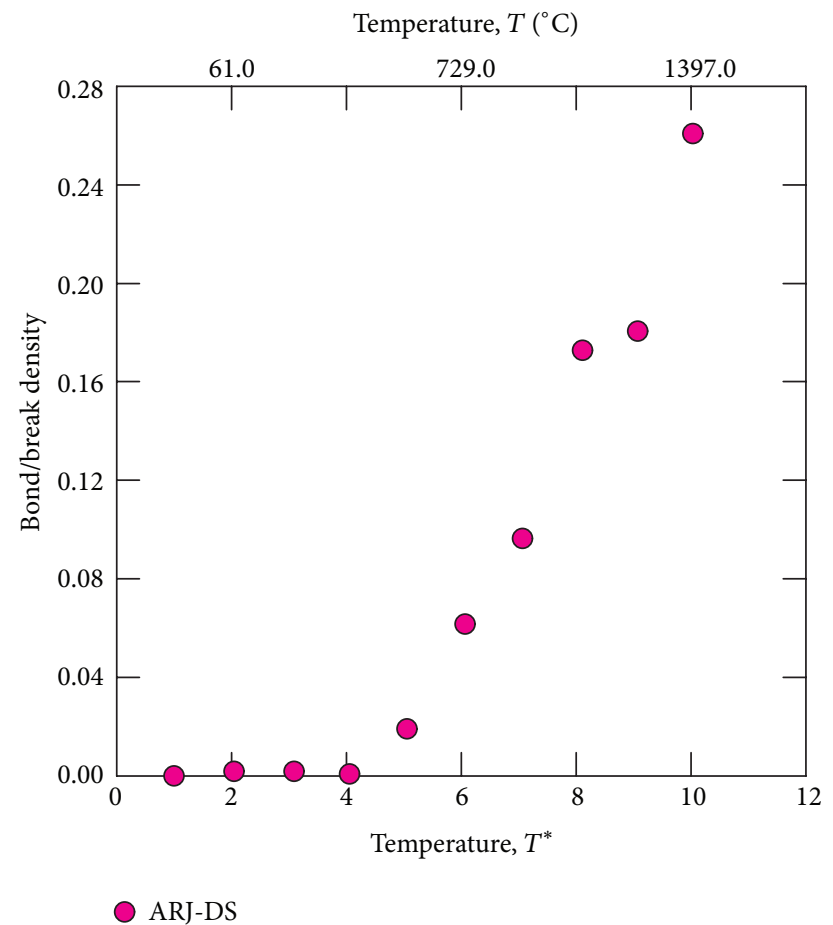

FIGURE 14: Effect of temperatures on the bond/break density of ARJ-DS on DLC surface.

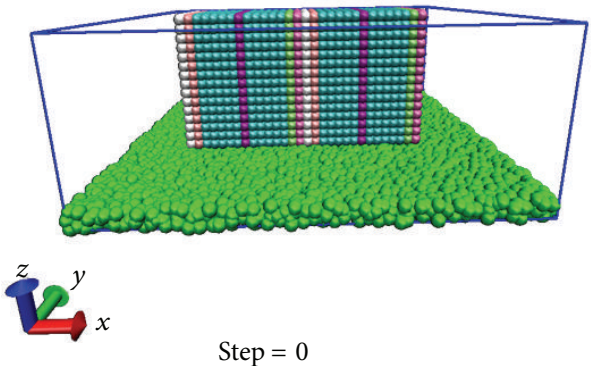

(a)
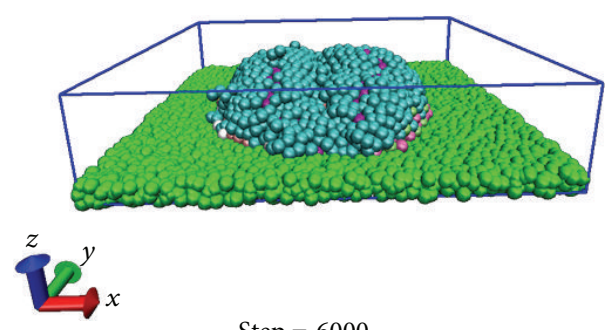

Step $=6000$

(b)

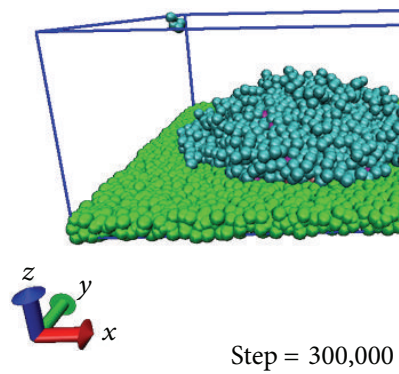

(c)

FIGURE 15: Snapshots of ARJ-DD on DLC surface at different time steps: (a) step =0; (b) step $=6000$; (c) step $=300,000$ at temperature $T^{*}=$ $4\left(668 \mathrm{~K}=395^{\circ} \mathrm{C}\right)$ with bond/break.

isothermally for 300,000 steps. Figure 18 shows the density of breaking of bonds of OHJ-DS on a DLC substrate with the increase of temperature. OHJ-DS is sensitive to breaking of bonds like ARJ-DS due to lack of thermal decomposition. But after temperature $T^{*}=6\left(1002 \mathrm{~K}=729^{\circ} \mathrm{C}\right)$, the density of breaking of bonds of OHJ-DS increases with the increase of temperature.
From the above studies on the density of breaking of bonds in nonfunctional lubricant PFPE Z, functional lubricants such as PFPE Zdol and PFPE Ztetraol, and multidented functional lubricants such as ARJ-DS, ARJ-DD, and OHJ-DS with temperature on the DLC substrate, the density of breaking of bonds of nonfunctional lubricant PFPE $\mathrm{Z}$ is the lowest because, with the rise of temperature, 


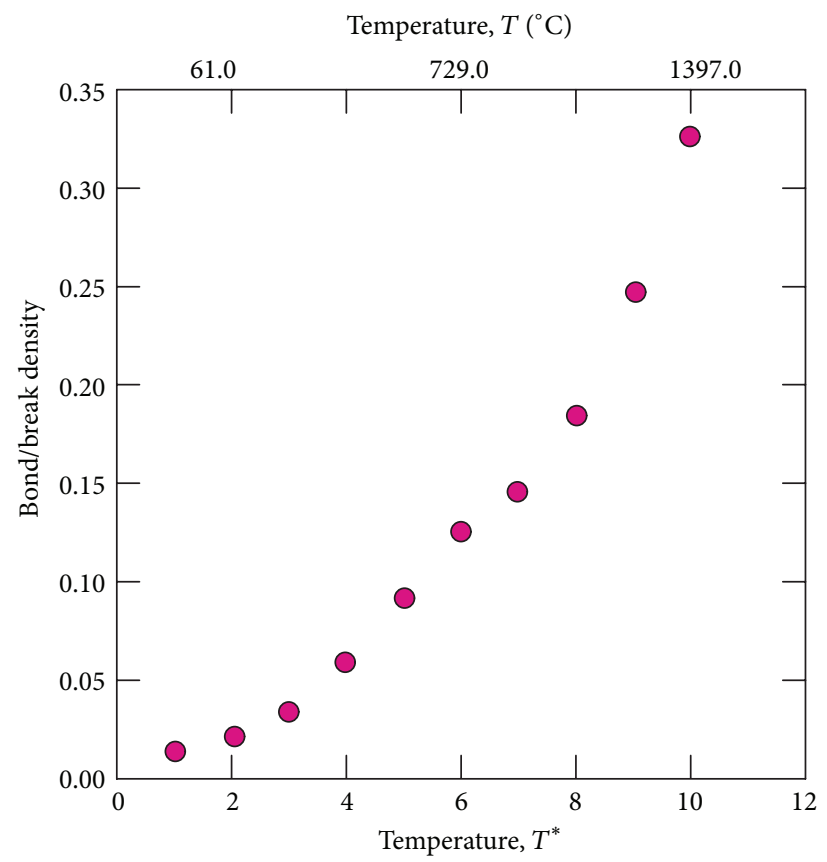

ARJ-DD

FIGURE 16: Effect of temperatures on the bond/break density of ARJ-DD on DLC surface.

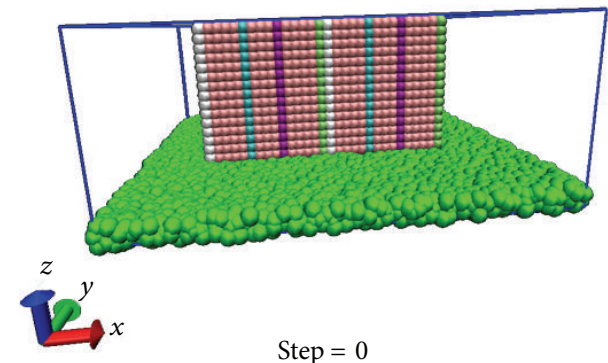

(a)
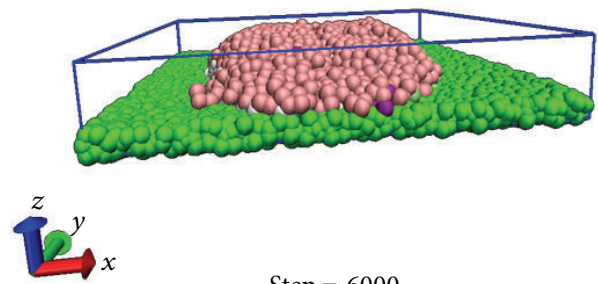

Step $=6000$

(b)

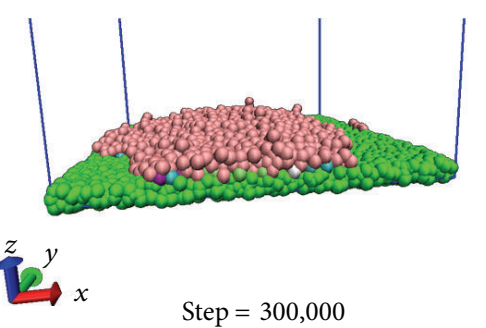

(c)

FIGURE 17: Snapshots of OHJ-DS on DLC surface at different time steps: (a) step =0; (b) step =6000; (c) step $=300,000$ at temperature $T^{*}=$ $4\left(668 \mathrm{~K}=395^{\circ} \mathrm{C}\right)$ with bond break.

most of the lubricants fly away from the DLC surface and for this reason there is less possibility to extend its bonds due to the low attraction force of its beads with the hard disk carbon overcoat. At HAMR condition PFPE $\mathrm{Z}$ is not suitable lubricant to lubricate hard disk carbon overcoat to reduce friction with carbon overcoat for protecting its magnetic layer. For the case of different types of functional lubricants mentioned here, there is less possibility to flying away from the hard disk carbon overcoat if their thermal decomposition does not happen due to breaking of bonds on account of increased kinetic energy with the increase of temperature. Among functional lubricants such as PFPE Zdol and PFPE Ztetraol and multidented functional lubricants such as ARJ-DS, ARJ-DD, and OHJ-DS, ARJ-DS is less sensitive to breaking of bonds due to thermal decomposition with the rise of temperature and it is concluded that ARJ-DS is 


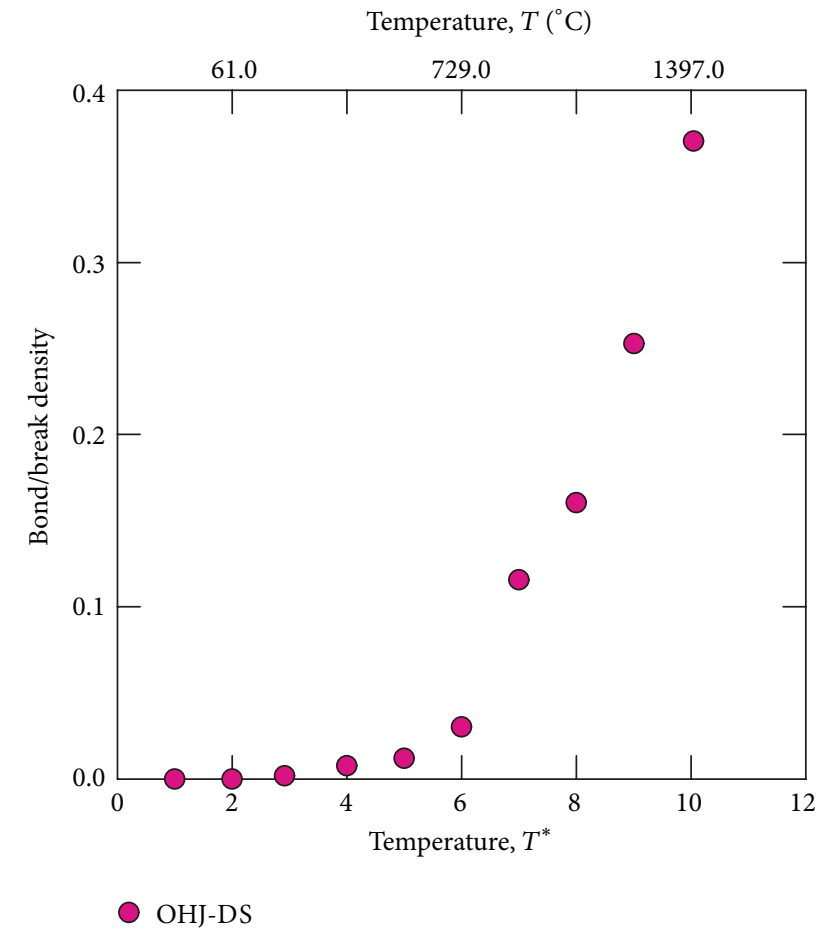

FIGURE 18: Effect of temperatures on the bond/break density of OHJDS on DLC surface.

the most suitable lubricant on a hard disk carbon overcoat of the mentioned functional lubricants here at HAMR condition.

\section{Conclusion}

With the increase of temperature the bond length between two beads gradually increases but there is allowable maximum bond length; bond can sustain up to this limit; if the bond stretches beyond this limit, the bond will break. In our simulation we consider the maximum allowable bond length $1.5 \sigma(1.05 \mathrm{~nm})$. From the analysis, it is observed that the effect of bond/break phenomenon disturbs the layering of lubricants on the DLC surface. Due to bond/break phenomenon, the functional beads accumulate on the hard disk substrate and broken short chains including nonfunctional beads fly away. It also observed the effect of bond/break on the end bead density of PFPE Zdol on the DLC surface. With the increase of temperature the bond/break density increases; that is, instability of the film increases when the temperature is increased. From the present studies it is concluded that although the density of breaking of bonds of PFPE Z on a DLC substrate with temperature is the lowest among all types of lubricants mentioned here, it is not at all suitable as a lubricant on a hard disk surface at HAMR condition because with the rise of temperature most of the PFPE $\mathrm{Z}$ lubricant molecules fly away from the DLC substrate due to thermal desorption. Among all of the functional lubricants PFPE Zdol, PFPE Ztetraol, ARJ-DS, ARJ-DD, and OHJ-DS, ARJ-DS shows less sensitivity to breaking of bonds on a carbon overcoat with the rise of temperature and negligible thermal desorption with the rise of temperature and for this reason, ARJ-DS is the most suitable lubricant which can be used as a lubricant on a carbon overcoat of a hard disk at HAMR condition.

\section{Conflict of Interests}

The authors declare that they have no conflict of interests regarding to the publication of this paper.

\section{References}

[1] L. D. Stevens, “The evolution of magnetic storage," IBM Journal of Research and Development, vol. 25, no. 5, pp. 663-675, 1981.

[2] J. M. Harker, D. W. Brede, R. E. Pattison, G. R. Santana, and L. G. Taft, "A quarter century of disk file innovation," IBM Journal of Research and Development, vol. 25, no. 5, pp. 677-689, 1981.

[3] S. X. Wang and A. M. Taratorin, Magnetic Information Storage Technology, Academic Press, London, UK, 1999.

[4] A. Moser, K. Takano, D. T. Margulies et al., "Magnetic recording: advancing into the future," Journal of Physics D, vol. 35, no. 19, pp. R157-R167, 2002.

[5] Z. Zhang, Y. C. Feng, T. Clinton et al., "Magnetic recording demonstration over $100 \mathrm{~Gb} / \mathrm{in}^{2}$," IEEE Transactions on Magnetics, vol. 38, no. 5, pp. 1861-1866, 2002.

[6] M. S. Jhon and H. J. Choi, "Lubricants in future data storage technology," Journal of Industrial and Engineering Chemistry, vol. 7, no. 5, pp. 263-275, 2001.

[7] B. Bhushan, "Magnetic media tribology: state of the art and future challenges," Wear, vol. 136, no. 1, pp. 169-197, 1990.

[8] M. S. Jhon, D. M. Phillips, S. J. Vinay, and C. T. Messe, "The dynamic behavior of thin-film lubricants," IEEE Transactions on Magnetics, vol. 35, no. 5, pp. 2334-2337, 1999.

[9] X. Ma, J. Gui, B. Marchon, M. S. Jhon, and C. L. Bauer, "Lubricant replenishment on carbon coated disks," in Proceedings of the IEEE International Magnetics Conference, 1999, Digests of INTERMAG 99 EP-21.

[10] R. Kono, S. Izumisawa, M. S. Jhon, C. A. Kim, and H. J. Choi, "Rheology of perfluoropolyether lubricants," IEEE Transactions on Magnetics, vol. 37, no. 4, pp. 1827-1829, 2001.

[11] S. K. Deb Nath, C. H. Wong, V. Sorkin, Z. D. Sha, Y. W. Zhang, and S.-G. Kim, "Study of the spreading of perfluoropolyether lubricants on a diamond-like carbon film," Tribology Transactions, vol. 56, no. 2, pp. 255-267, 2013.

[12] C.-Y. Chen, D. B. Bogy, and C. S. Bhatia, "Effects of backbone and endgroup on the decomposition mechanisms of PFPE lubricants and their tribological performance at the head-disk interface," Journal of Tribology, vol. 123, no. 2, pp. 364-367, 2001.

[13] C.-Y. Chen, C. S. Bhatia, J. Wei, W. Fong, and D. B. Bogy, "The decomposition mechanisms and thermal stability of ZDOL lubricant on hydrogenated carbon overcoats," Journal of Tribology, vol. 122, no. 2, pp. 458-464, 2000.

[14] J. Wei, W. Fong, D. B. Bogy, and C. S. Bhatia, "The decomposition mechanisms of a perfluoropolyether at the head/disk interface of hard disk drives," Tribology Letters, vol. 5, no. 2-3, pp. 203-209, 1998.

[15] T. E. Karis, V. J. Novotny, and R. D. Johnson, "Mechanical scission of perfluoropolyethers," Journal of Applied Polymer Science, vol. 50, no. 8, pp. 1357-1368, 1993.

[16] V. J. Novotny, X. Pan, and C. S. Bhatia, "Tribochemistry at lubricated interfaces," Journal of Vacuum Science \& Technology $A$, vol. 12 , no. 5 , article $2879,1994$. 
[17] R. Koka and F. Armatis, "Degradation of thin-film disk PFPE lubricants by ceramic powders," Tribology Transactions, vol. 40, no. 1, pp. 63-68, 1997.

[18] R. Koka, A. Holtz, and F. Armatis, "Tribology of different ceramic sliders on lubricated thin-film disks," Tribology Transactions, vol. 40, no. 1, pp. 156-162, 1997.

[19] J. Pacansky and R. J. Waltman, "Electron beam irradiation of polyperfluoroethers: experimental analysis of main-chain degradation," Chemistry of Materials, vol. 5, no. 4, pp. 486-494, 1993.

[20] G. Vurens, R. Zehringer, and D. Saperstein, in Surface Science Investigations in Tribology, Experimental Approaches, vol. 485 of ACS Symposium Series, p. 169, 1992.

[21] K. J. L. Paciorek and R. H. Kratzer, "Stability of perfluoroalkylethers," Journal of Fluorine Chemistry, vol. 67, no. 2, pp. 169-175, 1994.

[22] P. J. John and J. Liang, "Initial metal fluoride formation at metal/fluorocarbon interfaces," Journal of Vacuum Science \& Technology A, vol. 12, no. 1, pp. 199-203, 1994.

[23] P. H. Kasai, "Degradation of Perfluoropolyethers catalyzed by Lewis acids," Advances in Information Storage Systems, vol. 4, pp. 291-314, 1992.

[24] M. J. Zehe and O. D. Faut, "Acidic attack of perfluorinated alkyl ether lubricant molecules by metal oxide surfaces," Tribology Transactions, vol. 33, no. 4, pp. 634-640, 1990.

[25] W. Morales, "The decomposition of a commercial perfluoropolyalkylether on alpha and gamma catalytic aluminus," Tribology Transactions, vol. 39, no. 1, pp. 148-156, 1996.

[26] L. M. Ng, E. Lyth, M. V. Zeller, and D. L. Boyd, "Surface chemistry of Perfluoro Ethers: an infrared study of the thermal decomposition of $\left(\mathrm{C}_{2} \mathrm{~F}_{5}\right)_{2} \mathrm{O}$ on $\mathrm{Al}_{2} \mathrm{O}_{3}$," Langmuir, vol. 11, no. 1, pp. 127-135, 1995.

[27] S. Suzuki and F. E. Kennedy Jr., "Measurement of flash temperature and contact between slider and magnetic recording disk," IEEE Transactions on Magnetics, vol. 25, no. 5, pp. 3728-3730, 1989.

[28] B. D. Storm, University of California, Berkeley, Calif, USA, 1993.

[29] S. Mori and W. Morales, "Decomposition of perfluoroalkypolyethers (PFPE) in ultra-high vacuum under sliding conditions," Tribology Transactions, vol. 33, no. 3, pp. 325-332, 1990.

[30] B. Bhushan and Y. Cheng, "Wear and degradation mechanisms of magnetic thin-film rigid disks with different lubricants using mass spectrometry," Journal of Applied Physics, vol. 81, no. 8, pp. 5390-5392, 1997.

[31] X. Zhao, B. Bhushan, and C. Kajdas, "Lubrication studies of head-disk interfaces in a controlled environment. Part 2: degradation mechanisms of Perfluoropolyether lubricants," Proceedings of the Institution of Mechanical Engineers J: Journal of Engineering Tribology, vol. 214, no. 6, pp. 547-559, 2000.

[32] J. Liu, M. J. Stirniman, and J. Gui, "Catalytic decomposition of perfluoropolyether lubricants," IEEE Transactions on Magnetics, vol. 39, no. 2, pp. 749-753, 2003.

[33] S. Mori and W. Morales, "Tribological reactions of perfluoroalkyl polyether oils with stainless steel under ultrahigh vacuum conditions at room temperature," Wear, vol. 132, no. 1, pp. 111-121, 1989.

[34] P. H. Kasai and P. Wheeler, "Degradation of perfluoropolyethers catalyzed by aluminum chloride," Applied Surface Science, vol. 52, no. 1-2, pp. 91-106, 1991.

[35] P. H. Kasai, "Perfluoropolyethers: intramolecular disproportionation,” Macromolecules, vol. 25, no. 25, pp. 6791-6799, 1992.
[36] B. D. Strom, D. B. Bogy, R. G. Walmsley, J. Brandt, and C. S. Bhatia, "Gaseous wear products from perfluoropolyether lubricant films," Wear, vol. 168, no. 1-2, pp. 31-36, 1993.

[37] V. J. Novotny, X. Pan, and C. S. Bhatia, "Tribochemistry at lubricated interfaces," Journal of Vacuum Science \& Technology A, vol. 12, article 2879, 1994.

[38] G. H. Vurens, C. S. Gudeman, L. J. Lin, and J. S. Foster, "Mechanism of ultraviolet and electron bonding of perfluoropolyethers," Langmuir, vol. 8, no. 4, pp. 1165-1169, 1992.

[39] Z. Zhao and B. Bhushan, "Humidity effect on friction/stiction and durability of head-disk interface with polar perfluoropolyether lubricant," Journal of Applied Physics, vol. 81, no. 8, pp. 5387-5389, 1997.

[40] H. Liu and B. Bhushan, "Nanotribological characterization of molecularly thick lubricant films for applications to MEMS/NEMS by AFM," Ultramicroscopy, vol. 97, no. 1-4, pp. 321-340, 2003.

[41] B. Bhushan and H. Liu, Handbook of Nanotechnology, Springer, Heidelberg, Germany, 2004.

[42] V. N. Koinkar and B. Bhushan, "Microtribological studies of unlubricated and lubricated surfaces using atomic force/friction force microscopy," Journal of Vacuum Science and Technology A: Vacuum, Surfaces and Films, vol. 14, no. 4, pp. 2378-2391, 1996.

[43] V. N. Koinkar and B. Bhushan, "Micro/nanoscale studies of boundary layers of liquid lubricants for magnetic disks," Journal of Applied Physics, vol. 79, no. 10, pp. 8071-8075, 1996.

[44] X. Zhao and B. Bhushan, "Comparison studies on degradation mechanisms of perfluoropolyether lubricants and model lubricants," Tribology Letters, vol. 9, no. 3-4, pp. 187-197, 2001.

[45] X. Zhao and B. Bhushan, "Studies on degradation mechanisms of lubricants for magnetic thin-film rigid disks," Proceedings of the Institution of Mechanical Engineers J: Journal of Engineering Tribology, vol. 215, no. 2, pp. 173-188, 2001.

[46] B. Jiang, M. E. Selvan, D. J. Keffer, and B. J. Edwards, "A reactive molecular dynamics study of the thermal decomposition of perfluorodimethyl ether," Journal of Physical Chemistry B, vol. 113, no. 42, pp. 13670-13677, 2009.

[47] D. Pan, A. Ovcharenko, J. P. Peng, and H. Jiang, "Effect of lubricant fragments on lubricant transfer: a molecular dynamics simulation," IEEE Transactions on Magnetics, 2014.

[48] K. Chenoweth, S. Cheung, A. C. T. van Duin, W. A. Goddard III, and E. M. Kober, "Simulations on the thermal decomposition of a poly(dimethylsiloxane) polymer using the ReaxFF reactive force field," Journal of the American Chemical Society, vol. 127, no. 19, pp. 7192-7202, 2005.

[49] Q. Guo, S. Izumisawa, D. M. Phillips, and M. S. Jhon, "Surface morphology and molecular conformation for ultrathin lubricant films with functional end groups," Journal of Applied Physics, vol. 93, no. 10, pp. 8707-8709, 2003.

[50] Q. Guo, S. Izumisawa, M. S. Jhon, and Y. Hsia, "Transport properties of nanoscale lubricant films," IEEE Transactions on Magnetics, vol. 40, no. 4, pp. 3177-3179, 2004.

[51] Y.-T. Hsia, Q. Guo, S. Izumisawa, and M. S. Jhon, “The dynamic behavior of ultrathin lubricant films," Microsystem Technologies, vol. 11, no. 8-10, pp. 881-886, 2005.

[52] P. S. Chung, H. Park, and M. S. Jhon, "The static and dynamic responses of binary mixture perfluoropolyether lubricant filmsmolecular structural effects," IEEE Transactions on Magnetics, vol. 45, no. 10, pp. 3644-3647, 2009.

[53] P. H. Kasai, A. Wass, and B. K. Yen, "Carbon overcoat: structure and bonding of Z-DOL," Journal of Information Storage and Processing Systems, vol. 1, no. 3, pp. 245-258, 1999. 
[54] P. H. Kasai and A. M. Spool, "Z-DOL and carbon overcoat: bonding mechanism," IEEE Transactions on Magnetics, vol. 37, no. 2, pp. 929-933, 2001.

[55] H. Tani, T. Shimizu, N. Kobayashi, Y. Taniike, K. Mori, and N. Tagawa, "Study of molecular conformation of PFPE lubricants with multidentate functional groups on magnetic disk surface by experiments and molecular dynamics simulations," IEEE Transactions on Magnetics, vol. 46, no. 6, pp. 1420-1423, 2010.

[56] X. Li, Y. Hu, L. Jiang, and J. Zhang, "Spreading of droplets on lubricant-patterned substrates," The Journal of Chemical Physics, vol. 128, no. 19, Article ID 194904, 2008.

[57] S. Ogata, H. Zhang, K. Fukuzawa, and Y. Mitsuya, "Quantification of the surface morphology of lubricant films with polar end groups using molecular dynamics simulation: periodic changes in morphology depending on film thickness," Journal of Tribology, vol. 130, no. 2, Article ID 022301, 9 pages, 2008. 

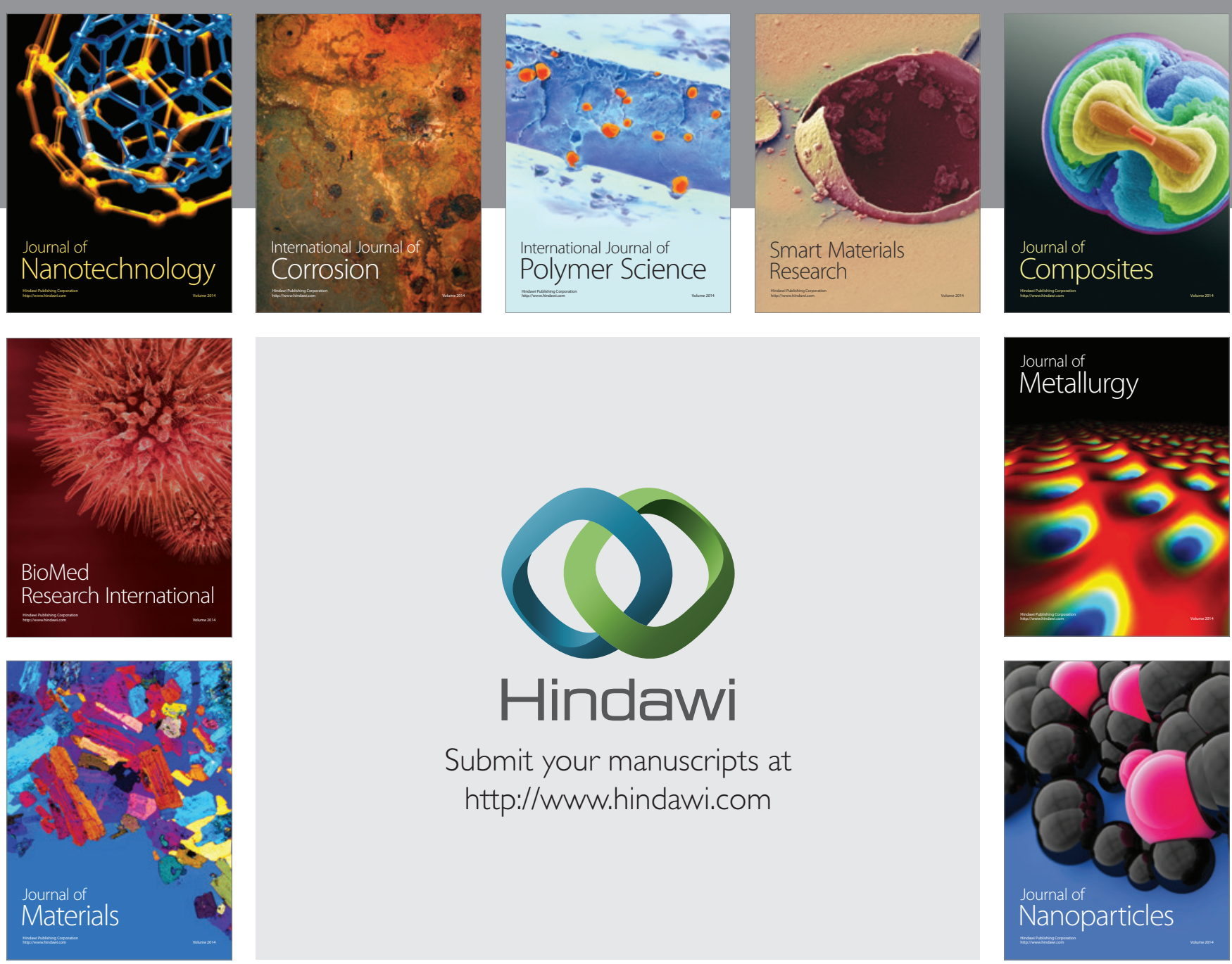

Submit your manuscripts at http://www.hindawi.com
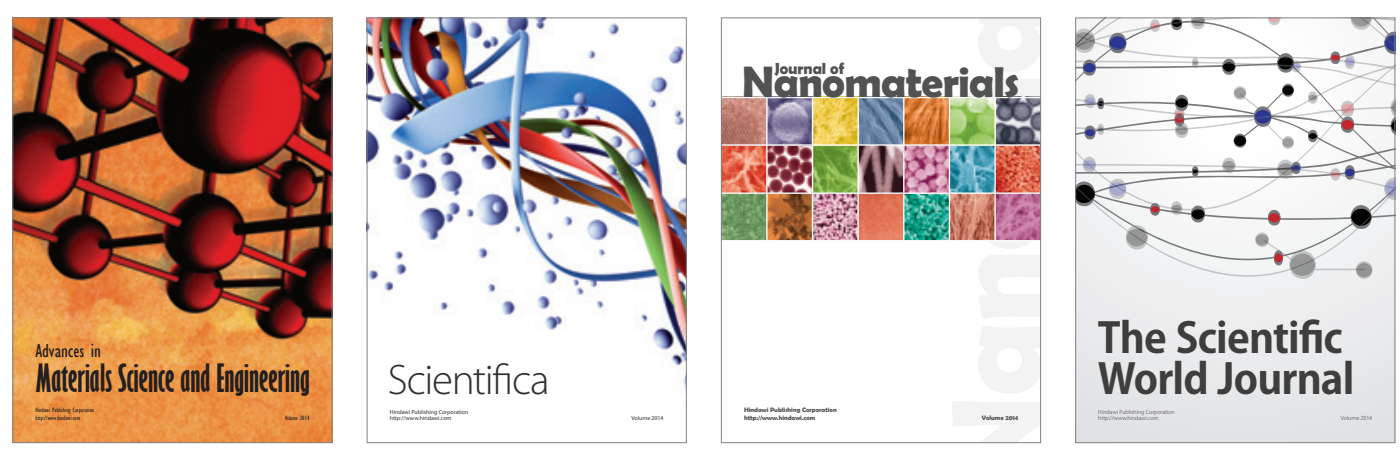

\section{The Scientific World Journal}
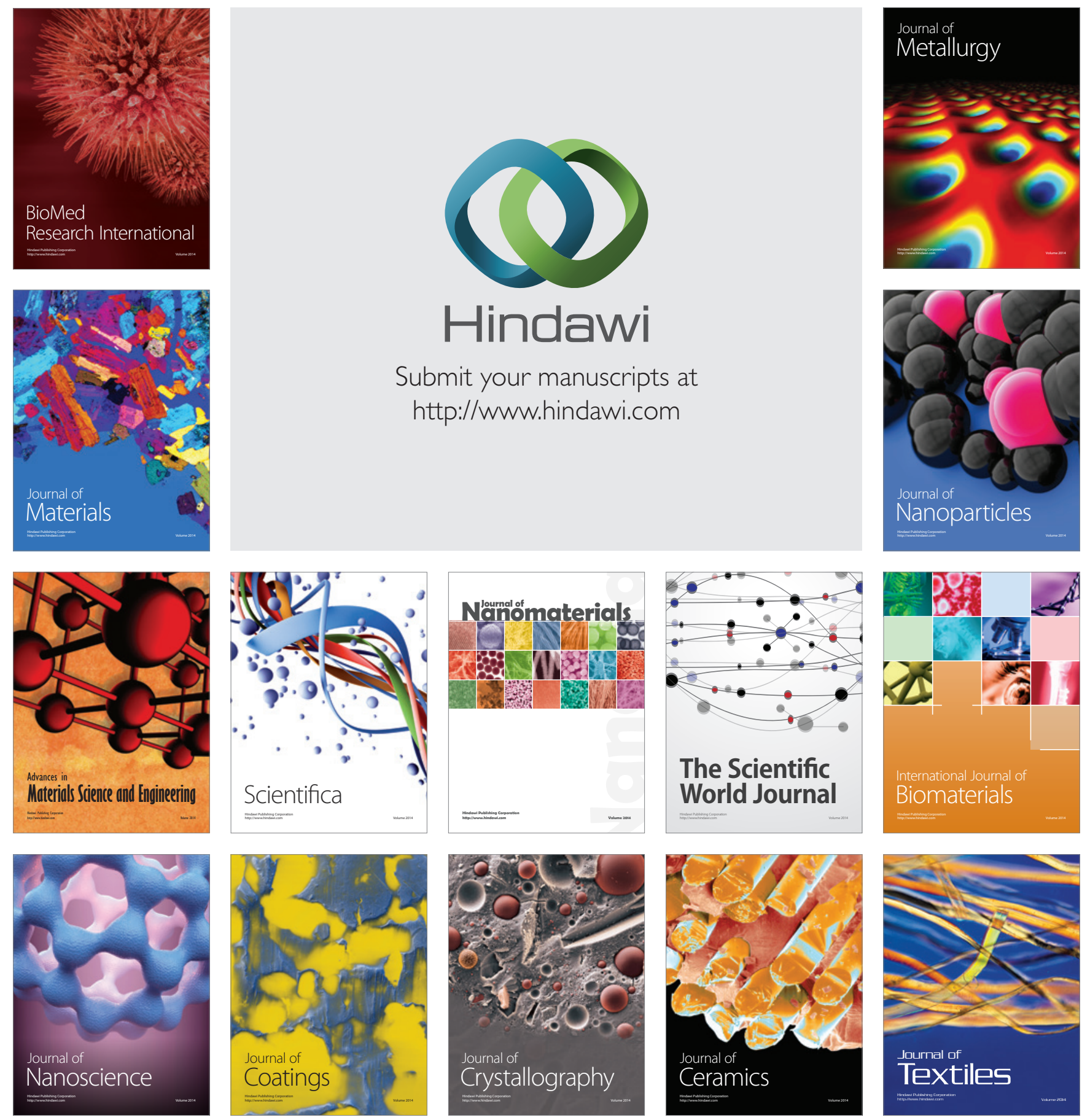